\title{
Optimal Monetary Policy
}

\section{In a Model with Agency Costs}

\section{Charles T. Carlstrom ${ }^{\mathrm{a}}$, Timothy S. Fuerst ${ }^{\mathrm{b}}$, Matthias Paustian ${ }^{\mathrm{c}}$}

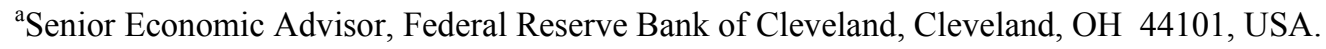 \\ charles.t.carlstrom@.clev.frb.org. \\ ${ }^{b}$ Professor, Department of Economics, Bowling Green State University, Bowling Green, OH 43403, USA; and \\ Senior Economic Advisor, Federal Reserve Bank of Cleveland. tfuerst@bgsu.edu. \\ ${ }^{\mathrm{c}}$ Economist, Bank of England, Threadneedle Street, London EC2R 8AH, England. \\ matthias.paustian@bankofengland.co.uk.
}

May 4, 2009

\begin{abstract}
This paper integrates a fully explicit model of agency costs into an otherwise standard Dynamic New Keynesian (DNK) model in a particularly transparent way. A principle result is the characterization of agency costs as endogenous mark-up shocks in an output-gap version of the Phillips curve. The model's utility-based welfare criterion is derived explicitly and includes a measure of credit market tightness which we interpret as a risk premium. The paper also fully characterizes optimal monetary policy and provides conditions under which zero inflation is the optimal policy. Finally, optimal policy can be expressed as an inflation targeting criterion that (depending upon parameter values) can be either forward or backward-looking.
\end{abstract}

We would like to thank Tony Yates and Jens Sondergaard for comments on an earlier draft of this paper. The views expresses in this paper are those of the authors only and do not represent the US Federal Reserve System or the Bank of England. 


\section{Introduction}

The macroeconomic events in the latter half of 2008 have sparked renewed interest in the role of financial shocks in the business cycle and the appropriate response of monetary policy to these shocks. This paper adds to this discussion by formally integrating a model of agency costs into an otherwise standard Dynamic New Keynesian (DNK) model. We do so in such a way that the agency-cost mechanism is quite transparent so that interactions between sticky prices and agency cost distortions are clearly identified. In addition our framework enables us to derive analytical expressions for the model-consistent welfare function.

We study the interaction of agency costs and sticky prices in a simple extension of the standard DNK model. Agency costs are modeled as a constraint on the firm's hiring of labor as in the hold-up problem of Kiyotaki and Moore (1997). We assume that the entrepreneur's hiring of one productive factor (labor) is constrained by entrepreneurial net worth. More generally, the constraint proxies for the effect that asset prices have on the ability of firms to finance operations. Net worth is accumulated over time via purchases of shares that are claims on the profit flow of sticky-price firms that produce the final good. This leads to a natural interplay between price stickiness and collateral constraints. In our setup, monetary policy affects dividends and thus share prices by altering the profit flow of these sticky price firms. Share prices in turn affect the hiring of labor via the collateral constraint.

How should monetary policy be conducted in such an environment? From a public finance perspective, prices stickiness implies that real marginal cost acts like a distortionary subsidy on both factor inputs, while agency costs act like a distortionary tax on only one input (the constrained input). This suggests that a tradeoff between stabilizing these two distortions 
may exist. We study this question formally by deriving the quadratic welfare function that is consistent with the underlying model and analyze optimal monetary policy in a linear-quadratic framework. Inflation and the output gap enter our loss function with the same coefficients as in the standard sticky price model. In addition, agency costs give rise to a new term that captures the variations in the tightness of the collateral constraint and that can be interpreted as a risk premium more generally. Thus, the recent concerns by central banks about credit market tightness and the volatility of risk premia have a counterpart in our welfare based loss function.

If credit constraints were absent from our model, we would obtain the standard result that central banks should fully stabilize inflation at all times in response to technology shocks. With agency costs and sticky prices, there is a special case where all distortions can again be closed in response to technology shocks by fully stabilizing inflation. This special case requires preferences that are logarithmic in consumption and an efficient initial value for the model's state variable. In this case net worth happens to move by exactly the amount required to hire the first best quantity of labor when inflation is fully stabilized. Outside of this special case, it is not optimal to fully stabilize inflation in response to technology shocks. However, the optimal deviation from inflation stability is small, so inflation stabilization is nearly optimal in this environment. Hence, the preferred interest rate rule should feature a strong anti-inflationary response, i.e. an inflation coefficient that is well in excess of the value originally proposed by Taylor.

We model financial shocks as shocks to the net worth of entrepreneurs and show that they act like endogenous markup shocks. Net worth shocks imply that inflation stabilization comes at the cost of increased fluctuations in the output gap and in the tightness of the collateral 
constraint that enter our loss function. Consequently, a temporary deviation from full price stability is warranted under optimal policy when financial sector shocks hit the economy.

We conclude this introduction with a brief review of the literature. Bernanke and Gertler (1989) provided the first attempt to build agency cost effects into an otherwise standard model of the business cycle. Their analysis was entirely qualitative. In a series of papers, Carlstrom and Fuerst $(1997,1998,2001)$ built on this earlier work to make the analysis quantitative. These papers were in the tradition of flexible prices. Bernanke, Gertler, and Gilchrist (1999) took the next logical step to integrate these agency cost effects into a DNK model. These models helped to quantity two distinct effects of agency costs: (1) a change in the economy's response to macroeconomic shocks because of the dynamics of borrower net worth, and (2) an additional source of shocks to the economy such as shocks to borrowers' balance sheets. But these previous analyses did not consider the question of optimal monetary policy.

Several recent papers have analyzed the performance of simple interest rate rules in agency cost models, e.g., Bernanke and Gertler (2001), Gilchrist and Leahy (2002), Faia and Monacelli (2007). Faia and Monacelli (2007) consider a model with sticky prices and credit frictions similar to Bernanke, Gertler and Gilchrist (1999). They employ numerical second-order approximations to evaluate welfare of a parametric family of interest rate rules. Faia and Monacelli (2007) find that strict inflation targeting is the welfare maximizing policy rule within the restricted set of rules. They argue that the marginal benefit from of neutralizing the price stickiness distortion largely outweighs the marginal benefit from neutralizing the credit friction distortion. Our linear-quadratic confirms this basic finding in the sense that the welfare weight on the risk premium is orders of magnitude smaller than the weight on inflation. In addition, Faia and Monacelli (2007) focus mainly on technology shocks. Our analysis considers shocks to 
net worth for which the optimal departure from price stability is larger than for productivity shocks.

Our work is most closely related to the papers by DeFiore and Tristani (2008) and Curdia and Woodford (2008). These authors also provide small scale sticky price models with credit frictions and characterize optimal policy within a linear-quadratic framework. Curdia and Woodford (2008) focus on interest rate spreads between bank's lending and deposit rates that arise because loans are costly to produce. The analysis of these credit frictions is limited to a reduced form relationship between credit spreads and macroeconomic conditions.

De Fiore and Tristani (2008) add a more complete underlying structure by including a costly state verification framework within the standard DNK model. But De Fiore and Tristani (2008) abstract from the endogenous evolution of net worth by assuming that entrepreneurs receive a fixed endowment in every period. This assumption simplifies matters but eliminates the endogenous state variable that is of fundamental importance to the agency cost mechanism. Further, both of these previous papers do not feature any feedback between asset prices and net worth of credit constrained agents. In contrast, the interplay between the share price, net worth and the agency cost distortion is central to the dynamics of our model.

The present paper proceeds as follows. In the next section we outline the model, culminating in an expression for the welfare criterion. Section three analyzes the model quantitatively. Section four concludes. 


\section{The Model.}

The model consists of households, entrepreneurs that produce intermediate goods, and sticky price firms that produce the final good. The basic structure is as follows. Households supply two types of labor input to the entrepreneurs. These entrepreneurs use a constant-returnsto-scale production function to produce an intermediate good using these two labor inputs. The entrepreneurial choice of one of the two labor inputs is constrained by accumulated net worth. This is the manifestation of agency costs in the model. The unconstrained input is necessary to ensure equilibrium existence. The combination of demand-determined output (from sticky prices) and constrained supply (from the net worth constraint) can often result in an overdetermined system. See the Appendix for details. The intermediate good is sold to monopolistically competitive final goods firms who use a linear production function to produce output. Pricing at this level is subject to Rotemberg (1982) adjustment costs. We now discuss each economic agent in turn.

\section{Households.}

The typical household consumes the final good $\left(c_{t}\right)$ and sells two types of labor input $\left(L_{t}\right.$ and $u_{t}$ ) to the entrepreneurs at factor prices $w_{t}$ and $r_{t}$. Preferences are given by

$$
U\left(c_{t}, L_{t}, u_{t}\right)=\frac{c_{t}^{1-\sigma}}{1-\sigma}-B_{1} \frac{L_{t}^{1+\theta}}{1+\theta}-B_{2} \frac{u_{t}^{1+\theta}}{1+\theta}
$$

This two-input framework can be interpreted in at least two ways. First, the aggregative household may be interpreted as a proxy for an economy with households that sell two distinct types of labor, but who insure each other in terms of final consumption. Alternatively, the second labor input can be interpreted as "capital utilization." Suppose that each household has a fixed level of capital, and they sell capital services to the entrepreneur at factor price $r_{t}$. Utilization of 
the capital stock $\left(u_{t}\right)$ causes a utility cost to the household. Both of these micro-level stories are consistent with the aggregative model analyzed here.

The household has access to two financial instruments. The first is a standard one-period bond. These are in zero net supply but are introduced to price the gross nominal interest rate denoted by $R_{t}$. Second, the household can purchase shares in the sticky price firm at price $Q_{t}$. These shares pay out dividends $D_{t}$. The aggregate supply of shares is normalized to unity. Ownership of these shares shifts back and forth endogenously between households and entrepreneurs. The input supplies, Fisher equation, and asset price equation are:

$$
\begin{aligned}
& U_{L}(t) / U_{c}(t)=w_{t}\left(1+w_{\text {sub }}\right) \\
& U_{u}(t) / U_{c}(t)=r_{t}\left(1+r_{s u b}\right) \\
& U_{c}(t)=E_{t} \beta U_{c}(t+1) R_{t} / \pi_{t+1} \\
& Q_{t} U_{c}(t)=E_{t} \beta U_{c}(t+1)\left[Q_{t+1}+D_{t+1}\right]
\end{aligned}
$$

where $\pi_{t}$ denotes the gross inflation rate, $w_{s u b}$ and $r_{s u b}$ are wage subsidies, and $E_{t}$ is the expectations operator.

\section{Entrepreneurs.}

We assume that there are a continuum of long-lived entrepreneurs with linear consumption preferences and inter-temporal discount rate $\beta$. Entrepreneurs hire two types of labor from households and use these inputs in a CRS production function to produce an intermediate good. Their profit function is given by:

$$
\operatorname{profits}_{t}=p_{t} L_{t}^{\alpha} u_{t}^{1-\alpha}-w_{t} L_{t}-r_{t} u_{t}
$$


where $p_{t}$ denotes the relative price of the intermediate good price (in terms of the final good), and $x_{t} \equiv L_{t}^{\alpha} u_{t}^{1-\alpha}$ will denote production of the intermediate good. The parameter, $\alpha$, governs the importance of agency costs in the model, if $\alpha=0$ the model collapses to the simple onesector sticky price model without agency costs. As mentioned above, $\alpha$ cannot be too large or the system becomes over-determined. ${ }^{1}$ Entrepreneurs face a collateral constraint on their hiring of the one labor input:

$$
w_{t} L_{t} \leq e_{t-1}\left(Q_{t}+D_{t}\right) \equiv n w_{t}
$$

where $e_{t-1}$ denotes the entrepreneur's holding of equity shares at the beginning of time-t, and $n w_{t}$ denotes their net worth. The collateral constraint is motivated by a hold-up problem as in Hart and Moore (1994). ${ }^{2}$ The model will be calibrated so that this constraint will always bind in equilibrium. ${ }^{3}$ The rigid constraint (6) implies that the loan-to-net-worth ratio is always unity. In contrast, Carlstrom and Fuerst (1997) assumed a costly-state-verification environment in which this leverage ratio varies endogenously with aggregate conditions, and the risk premium was linked to the leverage ratio. For typical calibrations this endogenous leverage ratio varies only modestly so that the rigid constraint (6) is imposed with little loss of generality but with a great increase in transparency.

\footnotetext{
${ }^{1}$ This modeling formulation is isomorphic to two sets of entrepreneurs, one using labor input $L_{t}$, and the other using labor input $u_{t}$. The former set of entrepreneurs is constrained by net worth, while the latter are not. These two inputs are then combined by a Cobb-Douglass production aggregator with coefficient $\alpha$. In this case, the coefficient $\alpha$ has the interpretation as the share of intermediate-good firms that are credit constrained.

${ }^{2}$ In the present context, the Hart-Moore (1994) hold-up problem would go something like this. After the L-input has been added to the production process, the entrepreneur must add his unique and inalienable human capital to the process for otherwise there would be no production. This means that ex post the entrepreneur can "hold up" the Linput supplier and force down her wages. To avoid this renegotiation problem, the L-input supplier requires the entrepreneur to back the promised wages with assets that can be seized if necessary. This creates the collateral constraint (6).

${ }^{3}$ More precisely, we log-linearize the model around a steady state in which this constraint binds and assume that it is also binding for small fluctuations around the steady state. Iacoviello (2005) has examined the possibility that collateral constraints could be only occasionally binding and concluded that this is quite unlikely in his environment given a reasonable calibration of the volatility of the shocks.
} 
Let $\phi_{t}$ denote the multiplier on the constraint (6). The optimization conditions include:

$$
\begin{aligned}
& \alpha p_{t} x_{t}=w_{t} L_{t}\left(1+\phi_{t}\right) \\
& (1-\alpha) p_{t} x_{t}=r_{t} u_{t}
\end{aligned}
$$

There is an alternative interpretation of $\phi_{t}$ that now suggests itself. From (7), $\phi_{t}$ is isomorphic to a model in which the $L$-input wage bill must be paid in advance of production at real interest rate $\phi_{t}$. Compared to the unfettered input choice (8), $\phi_{t}$ can thus be interpreted as a risk-premium on an intra-temporal loan, and fluctuations in $\phi_{t}$ are thus fluctuations in the risk premium.

Assuming that the collateral constraint binds, one can express (7) as

$$
\left(1+\phi_{t}\right)=\frac{\alpha p_{t} x_{t}}{n w_{t}}
$$

so that the risk premium is positively related to the output to net-worth ratio. ${ }^{4}$

Because of the collateral constraint firms will earn profits in equilibrium. These profits are given by

$$
\text { profits }_{t}=\alpha p_{t} x_{t}-n w_{t}=\alpha p_{t} x_{t}\left(\frac{\phi_{t}}{1+\phi_{t}}\right)
$$

In the neighborhood of the steady-state, profits are positive such that the rate of return on internal funds exceeds the time preference rate. Entrepreneur will thus desire to accumulate more net worth and postpone consumption. The entrepreneur's budget constraint is given by

$$
c_{t}^{e}+e_{t} Q_{t} \leq e_{t-1}\left(Q_{t}+D_{t}\right)+\text { profits }_{t}
$$

Using the binding collateral constraint and equilibrium profits we have:

$$
c_{t}^{e}+e_{t} Q_{t} \leq \alpha p_{t} x_{t}
$$

\footnotetext{
${ }^{4} \mathrm{~A}$ generalized version of the collateral constraint is given in the appendix.
} 
Linear preferences along with the profit potential from acquiring greater net worth to mitigate future agency costs implies that entrepreneurial consumption will always be zero in equilibrium. To ensure that entrepreneurs do not acquire so much collateral that the collateral constraint does not bind, we assume that fraction $(1-\gamma)$ of the entrepreneurs die each period, to be replaced by an equal number of new entrepreneurs each endowed with a trivial amount of net worth. These deaths are unexpected so the entrepreneurs do not consume their assets before dying. After dying, all assets of the entrepreneurs are redistributed to households. ${ }^{5}$ This simplifying assumption implies that the model's quadratic welfare function extends the standard loss function with only one additional term that accounts for agency costs.

\section{$\underline{\text { Sticky price firms. }}$}

Monopolistically competitive firms indexed by $j$ produce final goods $y_{t, j}$ that are aggregated to an output bundle according to $y_{t}=\left[\int_{0}^{1} y_{t, j}{ }^{(\varepsilon-1) / \varepsilon} d j\right]^{\varepsilon /(\varepsilon-1)}$ with $\varepsilon>1$. The final goods firms purchase the intermediate good from entrepreneurs at relative price $p_{t}$. The production function is given by $y_{t, j}=a_{t} x_{t, j}$, where productivity $a_{t}$ follows an exogenous AR(1) process. Since the production function is linear, real marginal cost is given by $z_{t}=p_{t} / a_{t}$. The final goods price is subject to a Rotemberg-style (1982) quadratic cost of price adjustment, which enter the profit function of firm $j$ as $\frac{\varphi}{2}\left[\left(p_{t, j}-p_{t-1, j}\right) / p_{t-1, j}\right]^{2} y_{t}$, with $\varphi \geq 0$. These costs

\footnotetext{
${ }^{5}$ See Carlstrom and Fuerst (1998) for a discussion of other methods of ensuring that the collateral constraint binds in equilibrium. For example, as in Carlstrom and Fuerst (1997), we could assume that entrepreneurs are risk-neutral and choose consumption optimally. To ensure that the collateral constraint binds, we could assume that entrepreneurs discount the future more heavily than do households. The Euler equation for entrepreneurial intertemporal consumption would be given by: $Q_{t}=\beta \gamma E_{t}\left(Q_{t+1}+D_{t+1}\right)\left(1+\phi_{t+1}\right)$, where $\gamma<1$ is the higher rate of discount. In log-deviations we would have: $\hat{q}_{t}=\beta E_{t} \hat{q}_{t+1}+(1-\beta) E_{t} \hat{d}_{t+1}+E_{t} \hat{\phi}_{t+1}$. We do not follow this approach as we would then need to include entrepreneurial consumption in the model which would needlessly complicate the welfare analysis.
} 
disappear from the linearized version of the social resource constraint as long as the gross inflation rate is unity in the steady state. Proposition 1 demonstrates that it is indeed optimal for a central bank that adopts a present value welfare criterion to deliver such a steady state inflation rate.

We use hatted variables throughout to denote their percentage deviation from the deterministic steady state. In a symmetric equilibrium, the Rotemberg price setting problem gives rise to the standard DNK Phillips curve given by

$$
\hat{\pi}_{t}=\lambda \hat{z}_{t}+\beta E_{t} \hat{\pi}_{t+1}+\lambda \epsilon_{t}^{\pi}
$$

where $\lambda \equiv(\varepsilon-1) / \varphi$, and $\epsilon_{t}^{\pi}$ is a mark-up shock with standard deviation $\sigma_{\pi}$. Monopolistic competition implies that these firms earn profits in equilibrium. These profits are paid out as dividends to shareholders of the sticky-price firms. These dividends are given by $D_{t}=a_{t} x_{t}(1-$ $\left.z_{t}\right)$

\section{A Tale of Two Distortions.}

A helpful interpretation of the model is revealed by considering the two labor input choices.

$$
\begin{aligned}
& \frac{U_{L}(t)}{U_{c}(t)}=\frac{z_{t}}{\left(1+\phi_{t}\right)} M P L_{t}\left(1+w_{s u b}\right) \\
& \frac{U_{u}(t)}{U_{c}(t)}=z_{t} M P U_{t}\left(1+r_{\text {sub }}\right)
\end{aligned}
$$


Here, MPU and $M P L$ denote the marginal product of $u$ and $L$, respectively. Increases in real marginal cost $\left(z_{t}\right)$ are isomorphic to a decrease in a distortionary tax on all labor income, while an increase in the agency cost distortion $\left(\phi_{t}\right)$ is isomorphic to an increase in a distortionary tax on labor income only from the choice of constrained labor, $L_{t}$. Hence, increases in $z_{t}$ will increase output via symmetric movements in both types of labor, while increases in $\phi_{t}$ will decrease output via an asymmetric decline in $L_{t}$.

We introduce wage subsidies to render the steady-state of the model efficient. The appendix provides the details. The appendix also outlines the entire model in log deviations. For present purposes, we will collapse the model into a smaller system that has a clear economic interpretation in terms of these two distortions. Let us begin by defining the output gap, etc., to be the difference in log deviations between actual output and the level of output when there are no price or credit frictions, $\hat{y}_{t}^{g} \equiv\left(\hat{y}_{t}-\hat{y}_{t}^{e f f}\right)$, where

$$
\hat{y}_{t}^{e f f}=\frac{(1+\theta)}{\sigma+\theta} a_{t}
$$

In this case, (A1)-(A2), (A7)-(A8), and (A11) can be combined to yield:

$$
\begin{aligned}
& \hat{u}_{t}^{g}=\frac{1}{\sigma+\theta} \hat{z}_{t}+\frac{\alpha(\sigma-1)}{(\sigma+\theta)(1+\theta)} \hat{\phi}_{t} \\
& \hat{L}_{t}^{g}=\frac{1}{\sigma+\theta} \hat{z}_{t}-\left[\frac{\sigma(1-\alpha)+(\alpha+\theta)}{(\sigma+\theta)(1+\theta)}\right] \hat{\phi}_{t} \\
& \hat{y}_{t}^{g}=\frac{1}{\sigma+\theta} \hat{z}_{t}-\frac{\alpha}{(\sigma+\theta)} \hat{\phi}_{t} \\
& \widehat{w}_{t}^{g}=\sigma \hat{y}_{t}^{g}+\theta \hat{L}_{t}^{g} \\
& \hat{r}_{t}^{g}=\sigma \hat{y}_{t}^{g}+\theta \hat{u}_{t}^{g}
\end{aligned}
$$


As noted above, output varies positively with marginal cost, and negatively with the agency cost distortion. Marginal cost affects both inputs symmetrically; while increases in the agency cost distortion necessarily lowers $L_{t}$ while having an ambiguous effect on $u_{t}$ (depending upon the size of $\sigma$ ). The Phillips curve (A9) and Fisher equation (A3) are given by:

$$
\begin{aligned}
& \hat{\pi}_{t}=\lambda \hat{z}_{t}+\beta E_{t} \hat{\pi}_{t+1}+\lambda \epsilon_{t}^{\pi} \\
& \frac{\sigma}{\sigma+\theta}\left(E_{t} \hat{z}_{t+1}-\hat{z}_{t}\right)-\frac{\alpha \sigma}{\sigma+\theta}\left(E_{t} \hat{\phi}_{t+1}-\hat{\phi}_{t}\right)=\hat{R}_{t}-E_{t} \hat{\pi}_{t+1}-\hat{\psi}_{t}
\end{aligned}
$$

where $\hat{\psi}_{t} \equiv \sigma\left(E_{t} \hat{y}_{t+1}^{\text {eff }}-\hat{y}_{t}^{\text {eff }}\right)$ is an exogenous fluctuation in the natural rate of interest. The agency cost movements $\hat{\phi}_{t}$ are endogenous to the model, so to close the model we need an expression for the dynamics of the agency cost distortion. As a first step, we use (A5) to solve for the asset price:

$$
\hat{q}_{t}=\frac{1}{(\sigma+\theta)}\left[(1+\sigma+\theta) \hat{z}_{t}-\alpha \hat{\phi}_{t}+(1+\theta) \hat{a}_{t}\right]-\hat{e}_{t}
$$

Equations (A6) and (A10) then provide a dynamic equation in $\mathrm{e}_{\mathrm{t}}$ :

$$
\hat{e}_{t}=\frac{1}{\beta}\left[\hat{e}_{t-1}+\hat{n}_{t}-\varepsilon(1-\beta) \hat{z}_{t}+\hat{\phi}_{t}\right]
$$

where $\hat{n}_{t}$ is an exogenous shock to the net worth of entrepreneurs with variance $\sigma_{n}^{2}$. Since $\hat{e}_{t-1}$ is the fraction of shares owned by entrepreneurs, $\hat{n}_{t}$ is a redistribution of wealth from households to entrepreneurs. The last dynamic relationship comes from using the asset-pricing formula (A4) and equation (23) scrolled forward:

$$
\begin{aligned}
& \alpha(1-\sigma) \hat{\phi}_{t}=[\alpha+\theta+\sigma(1-\alpha)] E_{t} \hat{\phi}_{t+1}- \\
& \quad(1+\theta) E_{t} \Delta \hat{z}_{t+1}+(\sigma-1)(1+\theta) E_{t} \Delta \hat{a}_{t+1}+(\sigma+\theta) E_{t} \hat{n}_{t+1}
\end{aligned}
$$

This completes the simplification of the model. 
In summary, the model is given by the two familiar DNK equations (20)-(21), and equations (23) and (24) which track the dynamic behavior of entrepreneurial wealth and the agency cost distortion. The model is then closed by articulating a rule for monetary policy. Several comments are in order.

First, if we set $\alpha=0$ so that the constrained input is not part of the production process, the model collapses to the familiar DNK model without the agency cost distortion. ${ }^{6}$ Hence, it is quite easy to consider the model with and without this distortion.

Second, agency costs manifest themselves as a distortion, $\hat{\phi}_{t}$, in the Fisher equation (21). Fluctuations in $\widehat{\phi}_{t}$ lead to an inefficient input mix (15)-(16), and thus fluctuations in the output gap (17). As noted earlier, one can interpret these movements as fluctuations in the risk premium on loans to finance the $L$-input. These effects are scaled by the production coefficient $\alpha$.

Finally, the addition of agency costs has no effect on the standard DNK pricing relationship (20). Inflation is still driven by fluctuations in marginal cost. However, if we write the pricing relationship in terms of the output gap (using (17)) we have:

$$
\hat{\pi}_{t}=\lambda(\sigma+\theta) \hat{y}_{t}^{g}+\alpha \lambda \hat{\phi}_{t}+\beta E_{t} \hat{\pi}_{t+1}+\lambda \epsilon_{t}^{\pi}
$$

Fluctuations in agency costs affect inflation in a manner symmetric to mark-up shocks, but with the key difference that agency costs evolve endogenously and are not simply exogenous shocks tacked on to the pricing relationship. Hence, whether agency costs need to be considered when estimating a Phillips curve depends upon whether marginal cost or the output gap are part of the empirical estimation. Relatedly, even if there are no mark-up shocks $\left(\epsilon_{t}^{\pi}\right)$, a monetary policy that stabilizes the output gap does not stabilize inflation.

\footnotetext{
${ }^{\mathbf{6}}$ This statement is true assuming that the central bank interest rate rule does not include a response to endogenous variables in (22)-(24) such as share prices or the risk premium.
} 


\section{$\underline{\text { Endogenous Agency Cost Dynamics with Flexible Prices }}$}

In the standard DNK model there are no endogenous state variables but agency costs naturally introduce net worth as an endogenous state variable. Hence, to understand the agency cost mechanism one needs to examine the endogenous dynamics of entrepreneurial net worthto what extent is current net worth propagated forward? The dynamic mechanism is particularly transparent for the case of flexible prices. In this DNK framework, these flexible-price dynamics are identical to a sticky price model in which the central bank stabilizes the inflation rate (assuming that there are no mark-up shocks). In this case, equations (23) and (24) become:

$$
\begin{aligned}
& E_{t} \hat{\phi}_{t+1}=A \hat{\phi}_{t}+\frac{A(1+\theta)(\rho-1)}{\alpha} \hat{a}_{t}-\rho_{n} \hat{n}_{t} \\
& \hat{\phi}_{t}=\beta \hat{e}_{t}-\left(\hat{e}_{t-1}+\hat{n}_{t}\right)
\end{aligned}
$$

where $A \equiv \frac{\alpha(1-\sigma)}{\alpha+\theta+\sigma(1-\alpha)}$, and $\left(\rho, \rho_{n}\right)$ are the autocorrelation in the productivity and net worth shock, respectively. The characteristic equation of this system is given by:

$$
h(x) \equiv \beta x^{2}-(1+\beta A) x+A .
$$

The two eigenvalues are $1 / \beta$ and $A$. Hence, there is determinacy if and only if $A$ is in the unit circle. There are three cases to consider depending upon the size of $\sigma$. If $\sigma=1, A=0$ so that there are no endogenous agency cost dynamics. If $\sigma<1$, then $0<\mathrm{A}<1$ so that there are nonoscillatory endogenous dynamics. In contrast, if $\sigma>1, \mathrm{~A}<0$ so that the stable root is negative and the agency dynamics are oscillatory. ${ }^{7}$

The equilibrium behavior under flexible prices is thus given by:

$$
\hat{e}_{t}=A \hat{e}_{t-1}+\left(\frac{A-\rho_{n}}{1-\beta \rho_{n}}\right) \hat{n}_{t}+\frac{A(1-\rho)(1+\theta)}{\alpha(1-\beta \rho)} \hat{a}_{t}
$$

\footnotetext{
${ }^{7}$ If $\alpha$ is too large and $\sigma>1$, the system is over-determined. See the appendix.
} 


$$
\hat{\phi}_{t}=(A \beta-1) \hat{e}_{t-1}+\left(\frac{A \beta-1}{1-\beta \rho_{n}}\right) \hat{n}_{t}+\frac{A \beta(1-\rho)(1+\theta)}{\alpha(1-\beta \rho)} \hat{a}_{t}
$$

Since $A \beta<1$, the risk premium is decreasing in entrepreneurial net worth. However, the response of net worth and the risk premium to the productivity shock depends upon the sign of A. For example, if $A>0(\sigma<1)$, then the risk premium and net worth accumulation are positively correlated with productivity shocks (and thus output). The opposite is true for $\mathrm{A}<0$ $(\sigma>1)$. In either case, the output gap is negatively correlated with the risk premium (see (17)).

The size of $\sigma$ matters because it determines the quantitative effect that entrepreneurial net worth has on share prices. The intuition goes something like this. When entrepreneurial net worth $\left(\hat{e}_{t-1}\right)$ is high the risk premium $\hat{\phi}_{t}$ is low, and output is high. If $\sigma<1$, this has a small effect on share prices, while if $\sigma>1$ this has a large effect on share prices. From (A5), entrepreneurial savings are given by $\hat{e}_{t}+\hat{q}_{t}=\hat{y}_{t}$. When $\sigma<1$, an increase in $\hat{e}_{t-1}$ increases output but has only a small effect on share prices implying that $\hat{e}_{t}$ must increase. The opposite is true for $\sigma>1$.

These flexible price dynamics are independent of the interest rate policy conducted by the central bank. As we add sticky prices things become more complicated because monetary policy no longer separates out but impacts the endogenous dynamics of $\hat{e}_{t}$. Suppose we close the system (20)-(21) and (23)-(24) with the simple interest rate rule $\hat{R}_{t}=\tau \hat{\pi}_{t}$, for $\tau>1$. We can then calculate the value of $\sigma$ consistent with the single stable eigenvalue of the system being zero. This cut-off value then demarcates the oscillatory vs. non-oscillatory dynamics. In particular we have that the dynamics are oscillatory if $\sigma>\frac{\lambda \tau}{1+\lambda \tau}$ and non-oscillatory if $\sigma<\frac{\lambda \tau}{1+\lambda \tau} .8$ Notice that this bound collapses to the flexible price result as $\lambda \rightarrow \infty$. Similarly, if monetary policy acts to

\footnotetext{
${ }^{8}$ This bound can be easily calculated from (20)-(21) and (24) by setting all shocks and future variables to zero. See the appendix for details.
} 
stabilize inflation, $\tau=\infty$, the dynamics of net worth are identical to the flexible price case because marginal cost does not respond to net worth. For smaller values of $\tau$, increases in $\hat{e}_{t-1}$ lower inflation and marginal cost as well. The distortion on constrained labor also decreases by more. These decreases make it more likely for $\hat{e}_{t}$ to also decline. In summary, with flexible prices $(\lambda=\infty)$, or a very aggressive monetary policy $(\tau=\infty)$, there are oscillatory dynamics if and only if $\sigma>1$. But with sticky prices, the region of oscillatory dynamics increases ( $\sigma>$ $\left.\frac{\lambda \tau}{1+\lambda \tau}\right)$ via the effect that entrepreneurial net worth has on marginal cost.'

\section{The Special Case of $\sigma=1$.}

Before proceeding to the welfare analysis, (28)-(29) demonstrate a key result. Recall that (absent mark-up shocks) these equations also describe the model under the case of sticky prices if the central bank stabilizes the inflation rate. Stabilizing the inflation rate also stabilizes marginal cost (20). For the case of $\sigma=1$, equation (29) implies that the risk premium does not respond to technology shocks. Hence, for the case of technology shocks and $\sigma=1$, if the economy begins at the steady-state $\left(\hat{e}_{t-1}=0\right)$, then a policy of stabilizing inflation eliminates both the marginal cost and agency cost distortion.

Why does zero inflation eliminate all distortions arising from technology shocks when $\hat{e}_{t-1}=0$ and $\sigma=1$ ? The agency cost distortion arises if and only if the $L$-input does not move by the efficient amount. The $L$-input is constrained by the value of the entrepreneur's net worth and thus fluctuates with movements in share prices:

\footnotetext{
${ }^{9}$ These oscillatory dynamics are much less likely to arise in the model with a generalized collateral constraint (see the appendix).
} 


$$
\widehat{w}_{t}+\hat{L}_{t}=\hat{e}_{t-1}+\beta \hat{q}_{t}+(1-\beta) \hat{d}_{t}=\hat{e}_{t-1}+\frac{(1+\theta)}{(\sigma+\theta)} \hat{a}_{t}+\frac{(1+\theta+\sigma)}{(\sigma+\theta)} \hat{z}_{t}-\frac{(\sigma+\theta+\alpha)}{(\sigma+\theta)} \hat{\phi}_{t}
$$

The efficient wage bill is given by:

$$
\widehat{w}_{t}^{e f f}+\widehat{L}_{t}^{e f f}=\frac{(1+\theta)}{(\sigma+\theta)} \hat{a}_{t}
$$

Note that if $\hat{e}_{t-1}=0$, fluctuations in productivity lead to fluctuations in the right-hand side of (A6) of precisely the magnitude needed to finance the efficient wage bill. This logic suggests that zero inflation might eliminate distortions for all values of $\sigma$, assuming that $\hat{e}_{t-1}=0$. The reason this is not the case is that entrepreneurial savings $\hat{e}_{t}$ in expression (24) is affected by fluctuations in productivity when $\sigma \neq 1$. The quantitative impact of alternative values of $\sigma$ will be investigated in Section 3.

\section{$\underline{\text { Welfare Criterion. }}$}

The transparency of the model allows for analytical expressions for the loss function. We first note that zero is the optimal steady-state inflation rate. The subsequent proposition provides two analytical expressions for the welfare function. The first is expressed in terms of the output gap, the second in the underlying distortions.

Proposition 1: The gross inflation rate that maximizes a present value welfare criterion is unity in the steady state regardless of whether subsidies exist that make the steady state efficient or not.

Proof: See appendix. 
Proposition 2: A quadratic approximation to the welfare function around a steady state with zero inflation is given by:

$\frac{U(t)-U^{*}(t)}{U_{c}(s s) c_{s s}} \approx-\frac{1}{2}\left[\frac{(\varepsilon-1)}{\lambda} \hat{\pi}_{t}^{2}+(\sigma+\theta)\left(\hat{y}_{t}^{g}\right)^{2}+\frac{\alpha(1-\alpha)}{1+\theta} \hat{\phi}_{t}^{2}\right]$

where $U^{*}(t)$ denotes welfare in a first best economy without agency or price adjustment costs. Using (17), we can alternatively express this in terms of the two underlying distortions:

$\frac{U(t)-U^{*}(t)}{U_{c}(s s) c_{s s}} \approx-\frac{1}{2}\left[\frac{(\varepsilon-1)}{\lambda} \hat{\pi}_{t}^{2}+\frac{\alpha[\theta+\alpha+\sigma(1-\alpha)]}{(1+\theta)(\sigma+\theta)} \hat{\phi}_{t}^{2}+\frac{1}{(\sigma+\theta)} \hat{z}_{t}^{2}-\frac{2 \alpha}{(\sigma+\theta)} \hat{\phi}_{t} \hat{z}_{t}\right]$

Proof: See appendix.

Proposition 2 has several important implications. First, agency costs add the variance of $\hat{\phi}_{t}$ to the loss function which captures the tightness of the collateral constraint. Recall that $\widehat{\phi}_{t}$ has the alternative interpretation as a risk premium on an intra-temporal loan for the L-input wage bill. Thus, the traditional concern by central banks about credit market tightness and the volatility of risk premia have a counterpart in our welfare-based loss function. When $\alpha=0$, the constrained labor input is not needed for production and the collateral constraint is not operative. Hence our loss function collapses to the standard loss function as in Woodford (2003). ${ }^{\mathbf{1 0}}$ For $\alpha>0$, the gap is no longer a sufficient statistic for welfare purposes as the composition of output (u-produced vs. L-produced) is relevant. When $\alpha=1$, all output is u-produced, so the gap is a sufficient statistic and the risk premium drops out of the gap-version of the welfare criterion.

Second, the objective function implies a preference for the two underlying distortions, $\widehat{\phi}_{t}$ and $\hat{z}_{t}$, to positively co-vary. This is not surprising as $\hat{\phi}_{t}$ acts as a tax and $\hat{z}_{t}$ like a subsidy.

\footnotetext{
10 The standard DNK welfare criterion assumes subsidies are paid to the firm to make marginal cost equal to unity in the steady-state. This implies that the welfare weight on inflation is $\frac{\epsilon}{\lambda}$. The weight here differs slightly because marginal cost is less than unity in the steady state. Instead, the subsidies we introduce to render the steady-state efficient are paid directly to households to boost labor supply. See Keen and Wang (2004) for details of the Rotemberg approximation.
} 
Finally, the importance of stabilizing inflation is quite clear. For typical calibrations, the coefficient on inflation is at least an order of magnitude larger than the coefficients on the risk premium and output gap. For example, for our baseline calibration, the weight on inflation is roughly 1000 times larger than the weight on the risk premium. Hence, the loss function implies a strong preference for stabilizing inflation, even at the cost of allowing the other distortions to vary. This is the principle reason that zero inflation is close to the optimal policy in a quantitative sense.

\section{Optimal Policy and Simple Rules}

In this section, we provide some analytical and quantitative results on optimal policy and the welfare losses of alternative policy rules. Under commitment, the policy maker maximizes

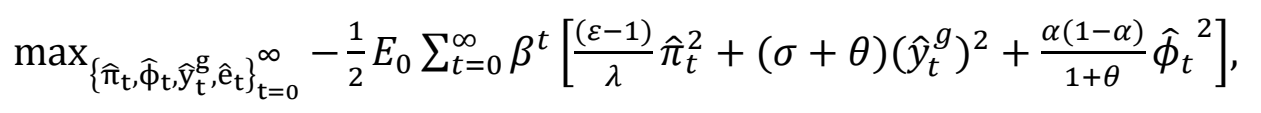

subject to the constraints

$$
\begin{aligned}
& \hat{\pi}_{t}=\lambda(\sigma+\theta) \hat{y}_{t}^{g}+\alpha \lambda \hat{\phi}_{t}+\beta E_{t} \hat{\pi}_{t+1}+\lambda \epsilon_{t}^{\pi}, \\
& \hat{e}_{t}=\frac{1}{\beta}\left\{\hat{e}_{t-1}-\varepsilon(1-\beta)(\sigma+\theta) \hat{y}_{t}^{g}+[1-\alpha \varepsilon(1-\beta)] \hat{\phi}_{t}+n_{t}\right\}, \\
& \hat{\phi}_{t}=(1+\theta) E_{t} \Delta \hat{y}_{\mathrm{t}+1}^{\mathrm{g}}-(1-\alpha) E_{t} \Delta \hat{\phi}_{t+1}-\frac{(\sigma-1)(1+\theta)}{\sigma+\theta} E_{t} \Delta \hat{a}_{\mathrm{t}+1}-E_{t} n_{\mathrm{t}+1}
\end{aligned}
$$

where (32)-(33) are (23)-(24) written in terms of the output gap. We assume that the policymaker is constrained by commitments in the initial period. See Woodford (2003) for details on the timeless perspective. 
Proposition 3: The optimal inflation target under commitment from a timeless perspective is given by:

$$
\begin{gathered}
\hat{\pi}_{t}=\left[\frac{\alpha \varepsilon(1-\beta)-1}{\varepsilon-1}\right] \Delta \hat{y}_{t}^{g}-\left[\frac{\alpha \varepsilon(1-\beta)(1-\alpha)}{(\varepsilon-1)(1+\theta)}\right] \Delta \hat{\phi}_{t}-\left[\frac{\alpha \varepsilon(1-\beta)(\sigma-1)+1+\theta}{(\varepsilon-1)(\sigma+\theta)}\right] \hat{X}_{t} \\
+\left[\frac{\varepsilon(1-\beta)[\alpha(\sigma-1)-(\sigma+\theta)]+1+\theta}{\beta(\varepsilon-1)(\sigma+\theta)}\right] \hat{X}_{t-1}
\end{gathered}
$$

The variable $\hat{X}_{t}$ is a lag-polynominal in $\Delta \hat{\phi}_{t}$ and $\Delta \hat{y}_{t}^{g}$ defined via the recursion:

$$
\begin{aligned}
& \hat{X}_{t}=\frac{\alpha \beta(1-\sigma)}{(\sigma+\theta+\alpha(1-\sigma))} E_{t} \hat{X}_{t+1}+E_{t} \Xi_{\mathrm{t}+1} \\
& \Xi_{\mathrm{t}} \equiv \frac{\alpha \beta(\sigma+\theta)\left[(1+\theta) \Delta y_{t}^{g}-(1-\alpha) \Delta \widehat{\phi}_{t}\right]}{(1+\theta)(\sigma+\theta+\alpha(1-\sigma))}
\end{aligned}
$$

Proof: See appendix.

Several comments are in order. First, optimal policy relates inflation to the first difference of the remaining variables in the loss function rather than to the levels. This feature is shared with the targeting criterion in the simple DNK model. Note that for $\alpha=0$ this condition is simply the targeting criterion from the standard DNK model, $\pi_{t}=-\frac{1}{\epsilon-1} \Delta y_{t}^{g a p}$

Second, the recursion in $\hat{X}_{t}$ implies that policy will be either forward-looking or backward-looking depending on the size of $\frac{\alpha \beta[(1-\sigma)]}{(\sigma+\theta+\alpha(1-\sigma))}$. This term is in the unit circle if and only if $\alpha(1+\beta)(\sigma-1)<(\sigma+\theta)$. If this inequality holds then policy is forward-looking with

$$
\hat{X}_{t}=\sum_{j=0}^{\infty}\left[\frac{\alpha \beta(1-\sigma)}{(\sigma+\theta+\alpha(1-\sigma))}\right]^{j} E_{t} \Xi_{\mathrm{t}+1+\mathrm{j}}
$$


Note that these coefficients are all positive only if $\sigma<1$. The sum of these future coefficients beyond one-period ahead is given by

$$
\sum_{j=1}^{\infty}\left[\frac{\alpha \beta(1-\sigma)}{(\sigma+\theta+\alpha(1-\sigma))}\right]^{j}=\left[\frac{\sigma+\theta+\alpha(1-\sigma)}{\sigma+\theta+\alpha(1-\beta)(1-\sigma)}\right]-1 \approx \frac{\alpha(1-\sigma)}{\sigma+\theta}
$$

For $\sigma=1$, no weight is placed on forecasts beyond one period ahead. For other values of $\sigma$ this sum remains small. Hence, the degree of forward-looking behavior (beyond one period) is modest and directly proportional to the degree of agency costs (the size of $\alpha)$. If $\alpha(1+\beta)(\sigma-$ 1) $>(\sigma+\theta)$, policy is backward-looking with

$$
\hat{X}_{t}=-\sum_{j=0}^{\infty}\left[\frac{\sigma+\theta+\alpha(1-\sigma)}{\alpha \beta(1-\sigma)}\right]^{j+1} \Xi_{\mathrm{t}-\mathrm{j}}
$$

The sum of these coefficients on current and lagged values is given by

$$
-\sum_{j=0}^{\infty}\left[\frac{\sigma+\theta+\alpha(1-\sigma))}{\alpha \beta(1-\sigma)}\right]^{j+1}=\left[\frac{\sigma+\theta+\alpha(1-\sigma)}{\sigma+\theta+\alpha(1-\beta)(1-\sigma)}\right]
$$

Again, the degree of backward-looking behavior is modest.

Finally, for $\sigma=\beta=1$ the targeting criterion is particularly simple in that only one lead and lag is included in the expression. We have:

$\hat{\pi}_{t}=-\frac{1}{(\varepsilon-1)} \Delta \hat{y}_{t}^{g}-\frac{\alpha}{(\varepsilon-1)}\left\{\mathrm{E}_{\mathrm{t}} \Delta \hat{y}_{t+1}^{g}-\mathrm{E}_{t-1} \Delta \hat{y}_{t}^{g}\right\}+\frac{\alpha(1-\alpha)}{(\varepsilon-1)(1+\theta)}\left\{\mathrm{E}_{\mathrm{t}} \Delta \hat{\phi}_{t+1}-\mathrm{E}_{t-1} \Delta \hat{\phi}_{t}\right\}$.

In comparison to the standard DNK criterion $\left(\hat{\pi}_{t}=-\frac{1}{(\varepsilon-1)} \Delta \hat{y}_{t}^{g}\right)$, the optimal inflation target now responds negatively to future gap growth and positively to forecasted increases in the risk premium, where the size of both of these effects is scaled by $\alpha$. If $\alpha=1$, then policy need not 
respond to the risk premium directly as future gap growth becomes a sufficient statistic for welfare purposes.

\section{Calibration.}

We now turn to a quantitative analysis of optimal policy. Parameters are set to standard values. The discount factor $\beta$ is set 0.99 . We set the elasticity in the CES aggregator $\varepsilon=10$, consistent with a markup of roughly $11 \%$. We calibrate the Rotemberg price adjustment cost parameter such that the coefficient on marginal cost in the Phillip curve is 0.052 . This resulting value for $\varphi$ is 173.08 . In a log-linearly equivalent Calvo price setting model such a slope implies that prices are fixed for 5 quarters on average. The share of constrained labor $\alpha$ is set to 0.5 . We think of this as the share of intermediate goods firms that are collateral constrained.

Our baseline calibration for the preference parameters follows Woodford (2003, page 172): $\sigma=0.16$ and $\theta=0.47$, implying large intertemporal and intratemporal elasticities. This implies that there are strategic complementarities in the model. Woodford argues that in a model without physical capital and investment spending, one needs a high intertemporal elasticity to match the interest-sensitivity of GDP. For sensitivity analysis we also consider the case of lower elasticities: $\sigma=\theta=2$. We assume that the total factor productivity follows an AR(1) process for autoregressive coefficient 0.95 , whereas net worth and markup processes are assumed to slightly less persistent with AR coefficients 0.9 . 


\section{Impulse Response Functions.}

Figures 1A-1B present the impulse responses to a positive technology shock for the two preference assumptions under two different versions of monetary policy: a policy that stabilizes inflation, and the optimal monetary policy under commitment. For the case of $\sigma=0.16$ and $\theta=$ 0.47, inflation behavior under optimal policy is essentially zero inflation, the annualized inflation rate barely rises to one basis point on impact. This occurs despite a sizeable output gap opening up for the first 4 quarters. This illustrates how agency costs break the divine coincidence present in the standard DNK model according to which both inflation and output gap can be stabilized simultaneously with technology shocks. Our model embeds a policy trade-off even for technology shocks, but this tradeoff is largely resolved in favor of stabilizing inflation. Under both polices, the nominal rate increases slightly, a peak of about 25 annualized basis points. Similarly, under both monetary policies the response of the risk premium and net worth are nearly identical. Consistent with (29), the technology shock increases the risk premium and net worth increases and responds in a hump-shaped manner. This is quite similar to the results in Carlstrom and Fuerst (1997). The basic mechanism is that the technology shock drives up the demand for credit faster than net worth can respond. Since the risk premium rises by more than the increase in marginal cost, the output gap declines.

For the alternative calibration of $\sigma=\theta=2$ in Figure 1B, the technology shock causes the risk premium to fall, and thus the output gap to rise (both are opposite the previous case). Optimal policy quickly eliminates this behavior so that the risk premium, marginal cost, and the gap are quickly driven back to zero. This is accomplished by a sharp decline, then equally sharp increase in the nominal (and real) interest rate. Again, the inflation behavior is nearly identical under the two policies. 
Figures 2A-2B present the complementary impulse responses to a negative net worth shock. ${ }^{11}$ The immediate impact of the shock is to sharply increase the risk premium. This increase leads to a decrease in output and the gap. As suggested by the welfare criterion, optimal policy calls for marginal cost and the risk premium to positively co-vary. This increase in marginal cost (decline in the mark-up) mitigates the contractionary effect of the increase in the risk premium so that the gap moves by less under optimal policy. This is accomplished by the cumulative real rate being lower under optimal policy than under zero inflation. (Recall that in this DNK model, the gap is proportional to the sum of all future real rates (see (21)). This is particularly clear in Figure 2A. Finally, note that when $\sigma=0.16$ and $\theta=0.47$, strategic complementarities imply that the Phillips curve trade-off between inflation and the output gap is very steep compared to our alternative calibration. Even a small increase in inflation implies that optimal policy can close about one third of the output gap that opens up in the first few quarters under a policy of full inflation stabilization. When $\sigma=2$ and $\theta=2$, the Phillips curve is not nearly as flat and the inflation-gap tradeoff is weak. Consequently, the output gap under optimal policy behaves more similarly to the gap under inflation stabilization.

\section{Quantifying Welfare Costs of Alternative Policies.}

In Tables $1 \mathrm{~A}$ and 1B we quantify the welfare losses for four different specifications of policy. Note that these losses are scaled by the variance of the innovations into the exogenous stochastic processes and are thus very small for typical calibrations of these variances, e.g., $\sigma_{a}^{2}=$ $(0.007)^{2}$

\footnotetext{
${ }^{11}$ See footnote 13 for a discussion of the size of the net worth shock.
} 
Along with the zero-inflation and optimal policy under commitment, we calculate the welfare losses for alternative interest rate rules. We consider simple rules of the form $\hat{R}_{t}=$ $\tau \hat{\pi}_{t}+\tau_{g} \hat{y}_{t}^{g}$. We set $\tau=1.5$ and $\tau_{\mathrm{g}}=0.5$ ("with gap") or $\tau_{\mathrm{g}}=0$ ("without gap"). We do not take a stand on the relative importance of the structural shocks, so we compute the welfare loss based on unconditional variances separately for each shock. Again, several comments are in order.

First, the agency cost distortions imply that the central bank cannot eliminate all welfare losses arising from technology shocks. Further, the presence of agency costs magnifies the welfare costs of all shocks, regardless of monetary policy. Second, as already suggested, inflation stabilization comes quite close to achieving the welfare level of the optimal monetary policy for all three shocks.

Third, the two Taylor rules do significantly worse than the zero inflation policy. As noted earlier, the welfare function places great weight on inflation, and under either Taylor rule the volatility of inflation is sharply increased.

Fourth, the importance of the slope of the Phillips curve for the output gap inflation tradeoff mentioned earlier is confirmed when comparing the welfare losses under net worth shocks in Tables 1A and 1B. For the calibration in Table 1A, the Phillips curve is flat and optimal monetary policy improves significantly upon full inflation stabilization. The parameterization for Table 1B implies that the trade off is weak and optimal policy does not improve upon inflation stabilization (up to rounding).

Fifth, and most interestingly, whether including the gap in the Taylor rule is efficacious depends upon the nature of the shock and the degree of agency costs. If agency costs are relatively unimportant (the bottom row in each entry), then responding to the gap is welfare- 
improving if there are technology shocks because an increase in the gap-response is equivalent to an increase in the inflation coefficient. However, this is not the case when there are mark-up shocks. When there are mark-up shocks, responding to the gap causes the volatility of inflation to increase relative to a rule that does not respond to the gap.

But agency costs add two interesting wrinkles to this result. First, agency costs manifest themselves as endogenous mark-up shocks when the Phillips curve is expressed in terms of the gap (see (25)). Hence, even if there are only technology shocks, the presence of agency costs can make responding to the gap a bad idea (see Table 1A). Second, for the case of net worth shocks, responding to the gap is always a bad idea, and the welfare cost can be quite large depending upon the variance of net worth shocks and how important agency costs are. Thus, the endogenous mark-up shocks coming from agency costs can be quite important.

\section{Optimal Policy in a Credit Crunch.}

US dollar investment grade corporate bond spreads have risen sharply over the course of the recent credit crunch. Spreads in sterling and Euro denominated bonds have behaved similarly, see Figure 3. ${ }^{12}$ What does the model predict for output, inflation, and monetary policy when hit by shocks that produce risk premia movements of this magnitude?

To answer such a question, we need to take a stand on the nature of the exogenous shocks and the stance of monetary policy. We assume that monetary policy is conducted according to the optimal targeting criterion developed above. To generate the risk premia movements, we

\footnotetext{
12 The spread data refers to aggregate indices of bonds rated BBB3 or higher. The spreads are option adjusted differences over government bond rates. The series is the quarterly average of daily data.
} 
pick a series of net worth innovations that induce the actual time series behavior of the risk premium from 1997: 1 to 2009: 1, with a steady state of $100 \mathrm{bp} .{ }^{13}$ The autocorrelation in the net worth shocks is set to $\rho_{n}=0.9$. We compute the model's predicted behavior of the output gap, inflation, the risk premium, and the ex-ante real rate under the optimal monetary policy and the policy that stabilizes inflation. This exercise sheds light on the policy trade-offs embedded in the model. We interpret the borrowing constraints as widespread across most firms and set $\alpha=$ 0.75. We use the preference calibration of $\sigma=.16$ and $\theta=0.47$.

These movements in the risk premium manifest themselves as endogenous mark-up shocks in (25). Note that in the standard DNK model $(\alpha=0)$, these movements in the risk premium have no effect.

Figure 4 shows the model behavior under optimal commitment and under full inflation stabilization. Under zero inflation, the gap and the risk premia are linked tightly by (25):

$$
\hat{y}_{t}^{g}=-\frac{\alpha}{(\sigma+\theta)} \hat{\phi}_{t}=-1.19 \hat{\phi}_{t}
$$

where the calculation uses our baseline calibration with $\alpha=0.75$. That is, a zero inflation policy causes the endogenous mark-up shocks to feed entirely into movements in the gap. This is clearly too much as the welfare function (30) implies that the weight on the gap is roughly five times larger than the weight on the risk premium $\left(\frac{(\sigma+\theta)(1+\theta)}{\alpha(1-\alpha)}\right)$. Hence, a policy of zero inflation allows the gap to move by too much relative to the risk premium.

\footnotetext{
${ }^{13}$ The size of these net worth shocks is not clearly predicted by the model in the following sense. If we consider the model with the generalized collateral constraint (see the appendix) the wealth shocks needed to achieve a desired path of the risk premium are scaled by the coefficient $b$. But the output response of a particular movement in the risk premium is largely unaffected by this parameter. Hence, for this risk-premium-matching experiment, the size of the net worth shock is not pinned down by the model.
} 
In contrast, optimal policy shifts more of the net worth shock on to a movement in the risk premium, and away from the gap. Optimal policy also allows for modest movements in inflation (12 basis points) to ameliorate the needed movements in the gap and the risk premium. The output gap is the discounted sum of future real rates. To limit the decline in the gap, the optimal policy has the real rate lie below its zero-inflation counterpart from 2009-2013. This is when the difference between the gaps under the two policies is magnified. Although the real rate is higher before 2009:1, the gap under optimal policy is smaller because of the anticipated lower real rates post 2009:1.

Overall, the predicted fall in output from this extraordinary rise in spreads seems somewhat small relative to the data. But the mapping from spreads to output depends crucially on the labor supply elasticity and the intertemporal elasticity of substitution. Both have been calibrated based on a standard sticky price model as outlined in Woodford (2003). The extra sluggishness implied by credit constraints in the present model could therefore justify lower values for both of these parameters. For sensitivity, we increase the labor supply elasticity to $1 / \theta$ $=10$ and report the results in Figure 5. As anticipated, the effects on the output gap are magnified: a decline of nearly $3 \%$ under the zero-inflation policy. This is still small compared to the gap behavior observed during this time period. The central bank tolerates these larger movements in the gap (for the same risk premium movement) because the relative weight on the gap (compared to the risk premium) is now smaller $\left(\frac{(\sigma+\theta)(1+\theta)}{\alpha(1-\alpha)}\right)$ than with $1 / \theta=2.2$. 


\section{Conclusion.}

This paper has developed a tractable model of credit frictions in an otherwise standard DNK model. A key implication of our model is that agency costs manifest themselves as endogenous mark-up shocks. Consequently, there generally is a trade-off between stabilizing inflation, the output gap and the risk premium, regardless of the type of shock hitting the economy - that is, there is no divine coincidence. Hence, the model provides a rationale for the central bank to consider credit frictions when setting policy. In particular, a measure of credit market tightness which we interpret as a risk premium enters directly into the central bank welfare criterion derived here. However, the DNK nature of the model implies that fluctuations in inflation are much more costly in welfare terms then variability of the output gap or the risk premium. Consequently, stabilizing inflation is near-optimal even if agency costs are quite severe.

This stylized model highlights the supply effects of agency costs. That is, the risk premium enters the model only via the Phillips curve. Hence, compared to zero inflation, optimal policy will magnify the response of the risk premium to a net worth shock. A more elaborate model would also include capital accumulation which would add a demand-side element to the model via changed demand for investment goods (or consumer durables). But our conjecture is that a model with both supply and demand forces will still result in optimal policy magnifying the movement of the risk premium in response to net worth shocks. Curiously, this model that endogenously introduces risk premia into the central bank's welfare criterion will lead the central bank to magnify risk premia movements compared to its inflation-targeting counterpart. 


\section{Table 1A $(\sigma=0.16, \theta=0.47)$}

\section{Welfare Losses under Different Monetary Policies}

The 3 entries in each cell correspond to $\alpha=0.5, \alpha=0.25$, and $\alpha=0.01$.

\begin{tabular}{|l|c|c|c|}
\hline & Technology shocks & Net Worth Shocks & Markup Shocks \\
\hline Optimal Commitment & $31 \sigma_{a}^{2}$ & $121 \sigma_{n}^{2}$ & $312 \sigma_{\pi}^{2}$ \\
& $18 \sigma_{a}^{2}$ & $53 \sigma_{n}^{2}$ & $320 \sigma_{\pi}^{2}$ \\
& $1 \sigma_{a}^{2}$ & $2 \sigma_{n}^{2}$ & $322 \sigma_{\pi}^{2}$ \\
\hline Inflation Stabilization & $32 \sigma_{a}^{2}$ & $138 \sigma_{n}^{2}$ & $383 \sigma_{\pi}^{2}$ \\
& $18 \sigma_{a}^{2}$ & $57 \sigma_{n}^{2}$ & $406 \sigma_{\pi}^{2}$ \\
& $1 \sigma_{a}^{2}$ & $2 \sigma_{n}^{2}$ & $418 \sigma_{\pi}^{2}$ \\
\hline Taylor Rule with gap & $373 \sigma_{a}^{2}$ & $1472 \sigma_{n}^{2}$ & $6085 \sigma_{\pi}^{2}$ \\
& $89 \sigma_{a}^{2}$ & $391 \sigma_{n}^{2}$ & $5868 \sigma_{\pi}^{2}$ \\
& $16 \sigma_{a}^{2}$ & $2 \sigma_{n}^{2}$ & $5726 \sigma_{\pi}^{2}$ \\
\hline Taylor Rule without gap & $173 \sigma_{a}^{2}$ & $163 \sigma_{n}^{2}$ & $761 \sigma_{\pi}^{2}$ \\
& $117 \sigma_{a}^{2}$ & $60 \sigma_{n}^{2}$ & $519 \sigma_{\pi}^{2}$ \\
& $99 \sigma_{a}^{2}$ & $2 \sigma_{n}^{2}$ & $424 \sigma_{\pi}^{2}$ \\
\hline
\end{tabular}

(We assume that the TFP follows an AR(1) process with autoregressive coefficient 0.95 , whereas net worth and markup processes are assumed to slightly less persistent with AR coefficients 0.9 . Welfare losses are scaled by the variance of the innovation in the exogenous processes for TFP $\left(\sigma_{a}^{2}\right)$, net worth $\left(\sigma_{n}^{2}\right)$ and markup $\left(\sigma_{\pi}^{2}\right)$, respectively. Each table entry is multiplied by 100.) 


\section{Table 1B $(\sigma=2, \theta=2)$}

\section{Welfare Losses under Different Monetary Policies}

The 3 entries in each cell correspond to $\alpha=0.5, \alpha=0.25$, and $\alpha=0.01$.

\begin{tabular}{|l|c|c|c|}
\hline & Technology shocks & Net Worth Shocks & Markup Shocks \\
\hline Optimal Commitment & $4 \sigma_{a}^{2}$ & $39 \sigma_{n}^{2}$ & $69 \sigma_{\pi}^{2}$ \\
& $2 \sigma_{a}^{2}$ & $21 \sigma_{n}^{2}$ & $64 \sigma_{\pi}^{2}$ \\
& $0 \sigma_{a}^{2}$ & $1 \sigma_{n}^{2}$ & $61 \sigma_{\pi}^{2}$ \\
\hline Inflation Stabilization & $4 \sigma_{a}^{2}$ & $39 \sigma_{n}^{2}$ & $75 \sigma_{\pi}^{2}$ \\
& $2 \sigma_{a}^{2}$ & $21 \sigma_{n}^{2}$ & $70 \sigma_{\pi}^{2}$ \\
& $0 \sigma_{a}^{2}$ & $1 \sigma_{n}^{2}$ & $66 \sigma_{\pi}^{2}$ \\
\hline Taylor Rule with gap & $1022 \sigma_{a}^{2}$ & $418 \sigma_{n}^{2}$ & $1696 \sigma_{\pi}^{2}$ \\
& $941 \sigma_{a}^{2}$ & $111 \sigma_{n}^{2}$ & $1533 \sigma_{\pi}^{2}$ \\
& $960 \sigma_{a}^{2}$ & $1 \sigma_{n}^{2}$ & $1518 \sigma_{\pi}^{2}$ \\
\hline Taylor Rule without gap & $1630 \sigma_{a}^{2}$ & $100 \sigma_{n}^{2}$ & $521 \sigma_{\pi}^{2}$ \\
& $1512 \sigma_{a}^{2}$ & $34 \sigma_{n}^{2}$ & $284 \sigma_{\pi}^{2}$ \\
& $1495 \sigma_{a}^{2}$ & $1 \sigma_{n}^{2}$ & $277 \sigma_{\pi}^{2}$ \\
\hline
\end{tabular}

(We assume that the TFP follows an AR(1) process with autoregressive coefficient 0.95 , whereas net worth and markup processes are assumed to slightly less persistent with AR coefficients 0.9 . Welfare losses are scaled by the variance of the innovation in the exogenous processes for TFP $\left(\sigma_{a}^{2}\right)$, net worth $\left(\sigma_{n}^{2}\right)$ and markup $\left(\sigma_{\pi}^{2}\right)$, respectively. Each table entry is multiplied by 100 .) 


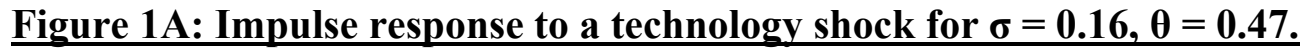
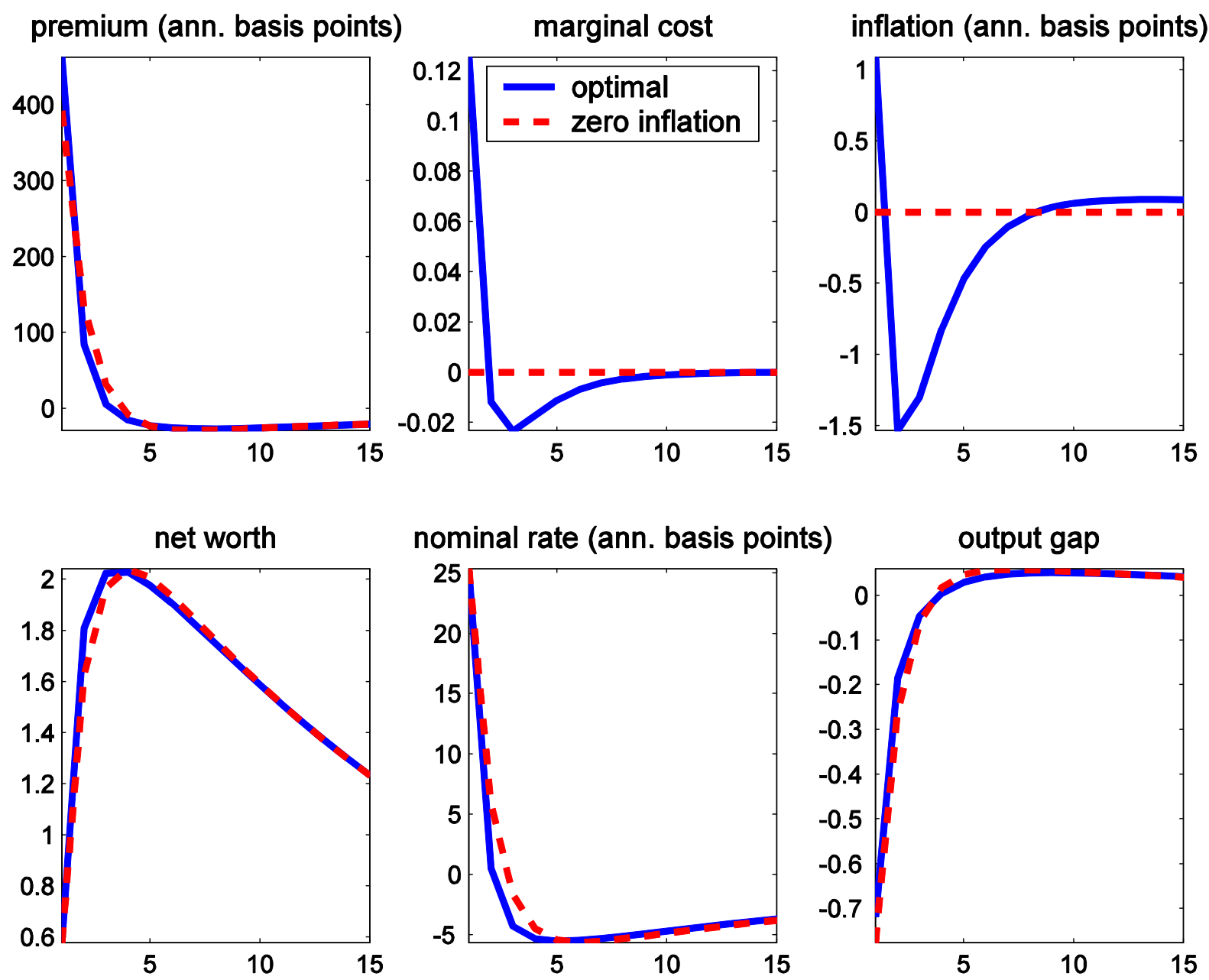

Note: The $\mathrm{x}$-axis measure quarters after the shock. The y-axis measures percentage deviations from the steady state for all variables except for the premium, inflation and the nominal rate where it measures the deviations in annualized basis points. 
Figure 1B: Impulse response to a technology shock for $\sigma=2, \theta=2$.
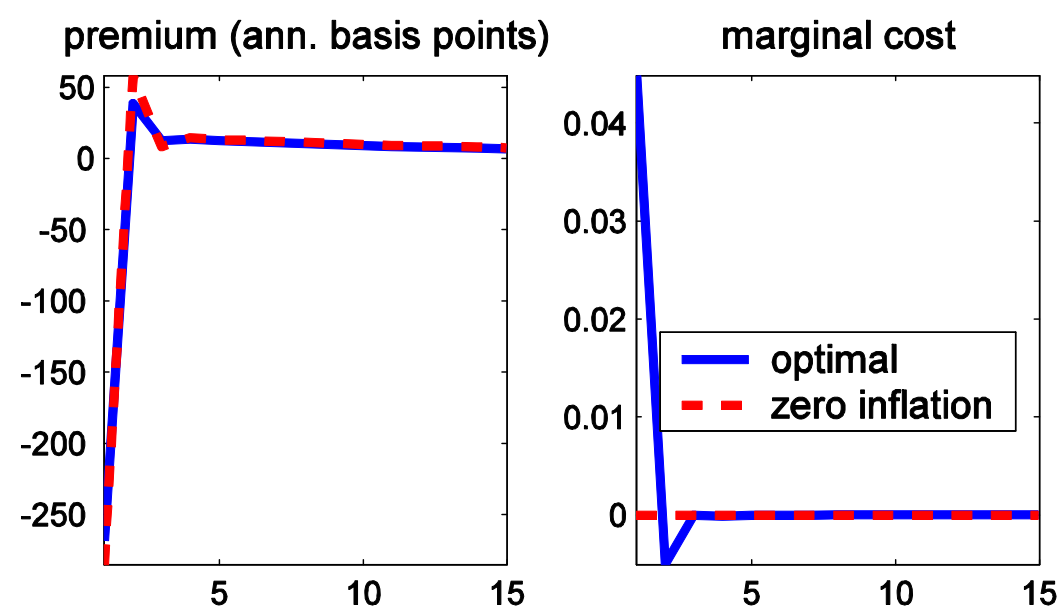

inflation (ann. basis points)

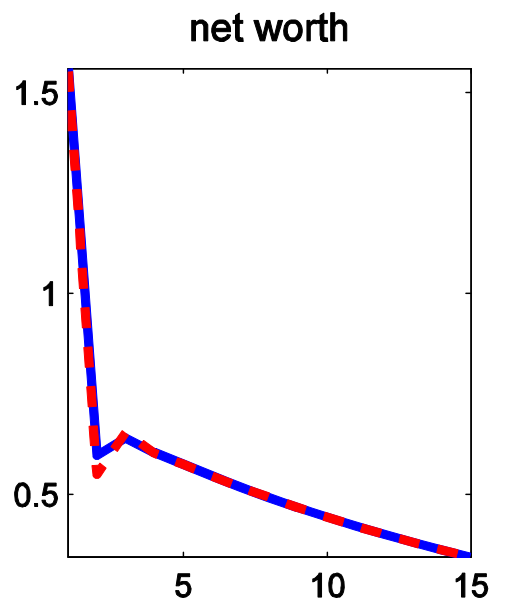

nominal rate (ann. basis points)
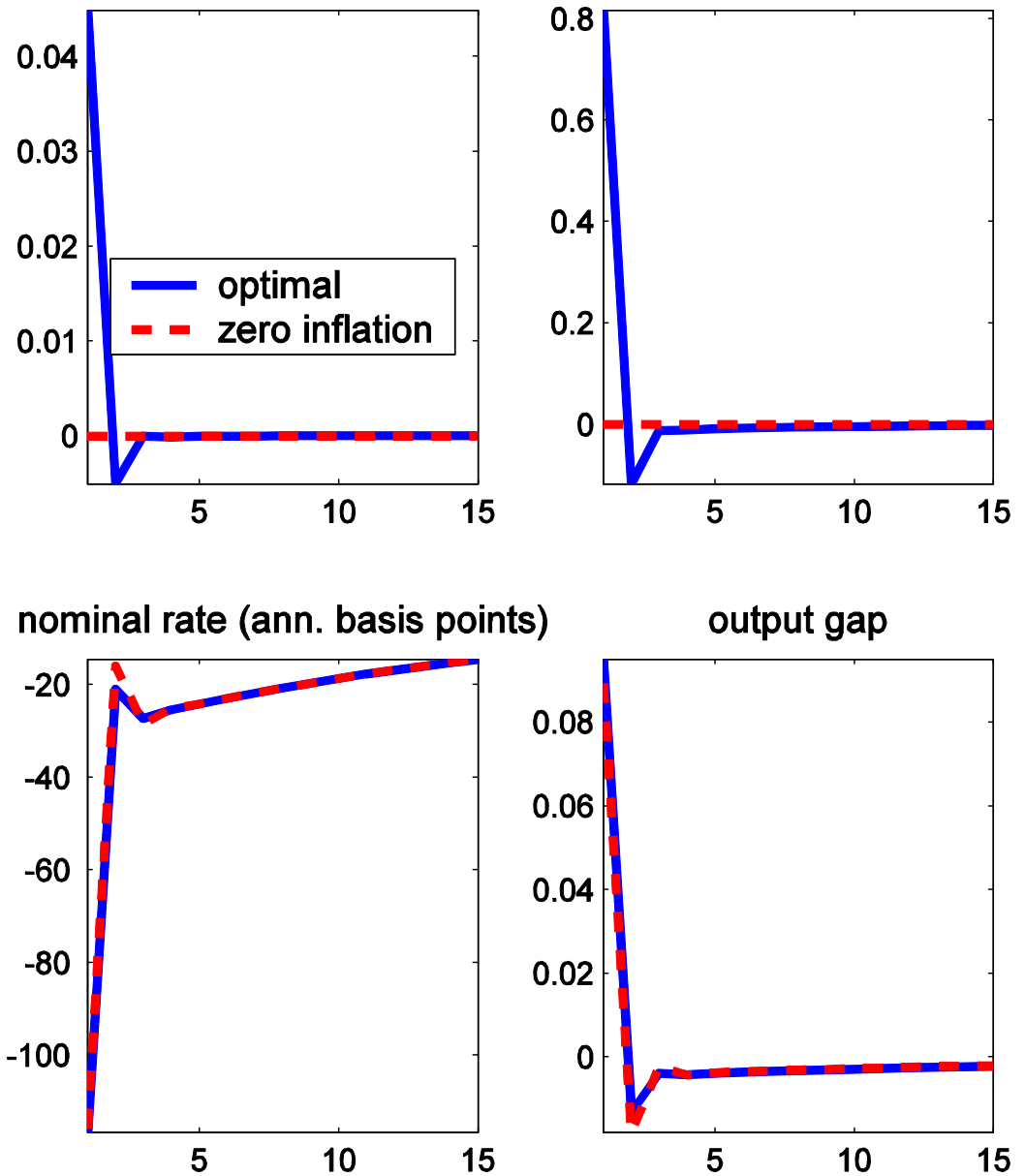

Note: See Figure 1A. 
Figure 2A: Impulse response to a net-worth shock for $\sigma=0.16, \theta=0.47$.
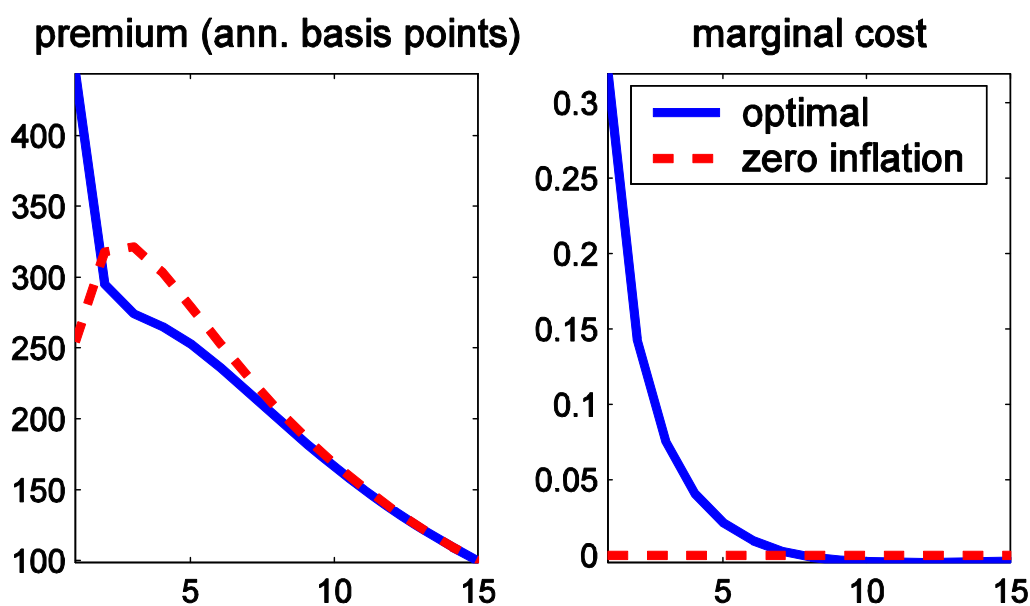

inflation (ann. basis points)
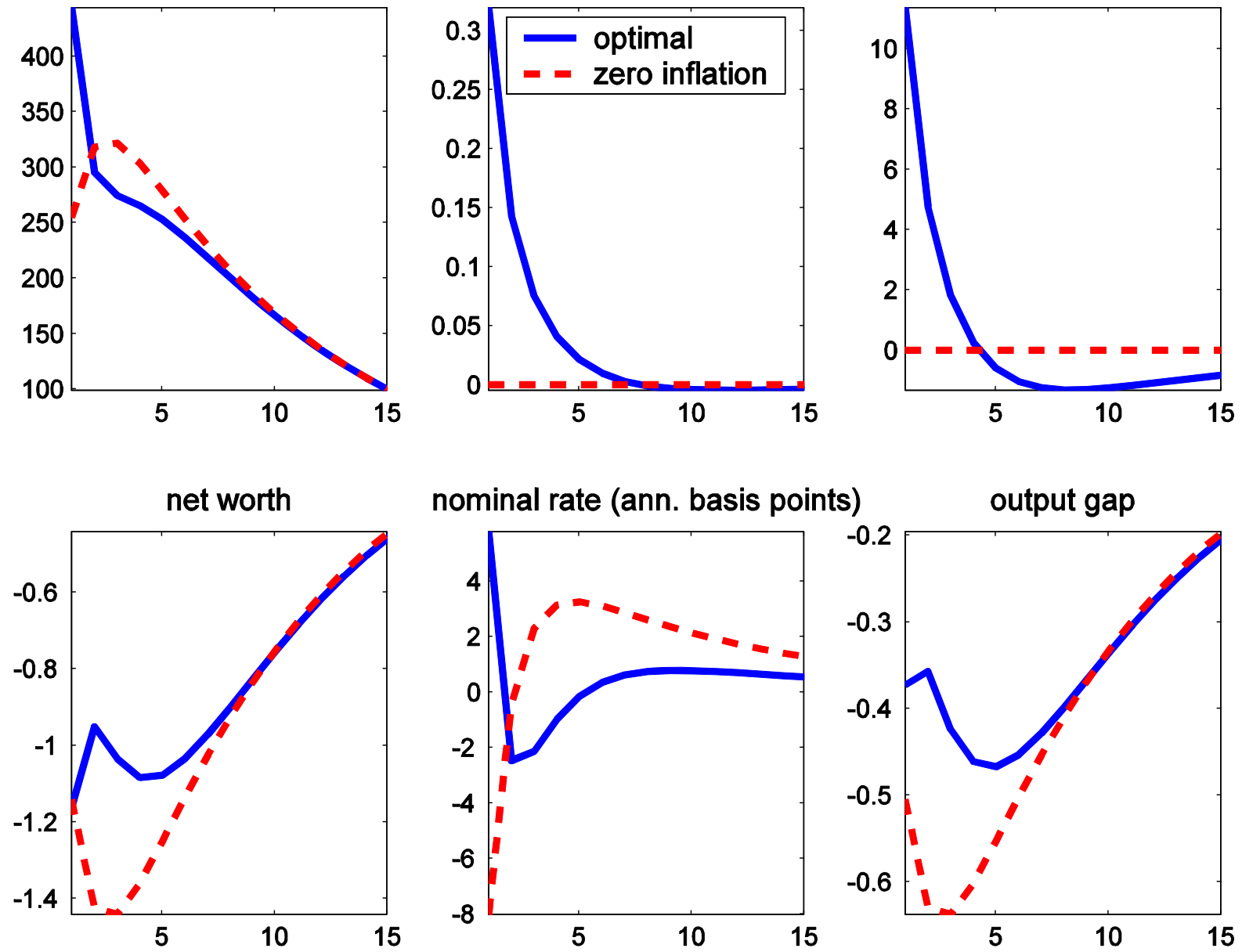

Note: See Figure 1A. 
Figure 2B: Impulse response to a net-worth shock for $\sigma=2, \theta=2$.
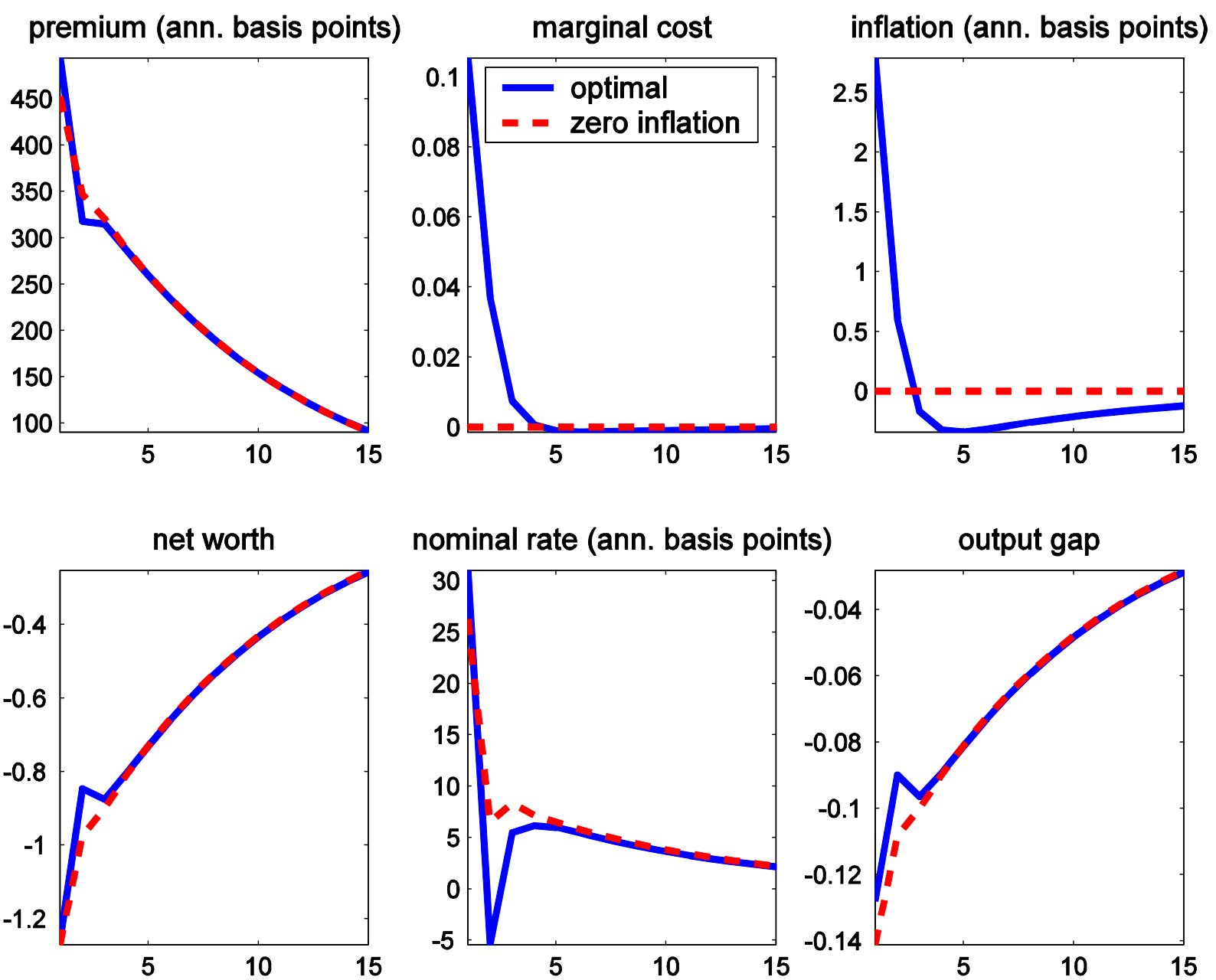

Note: See Figure 1A.

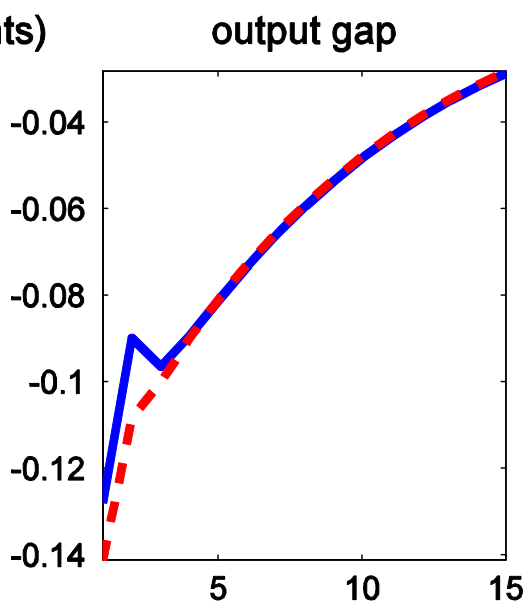


Figure 3: Corporate bond spreads

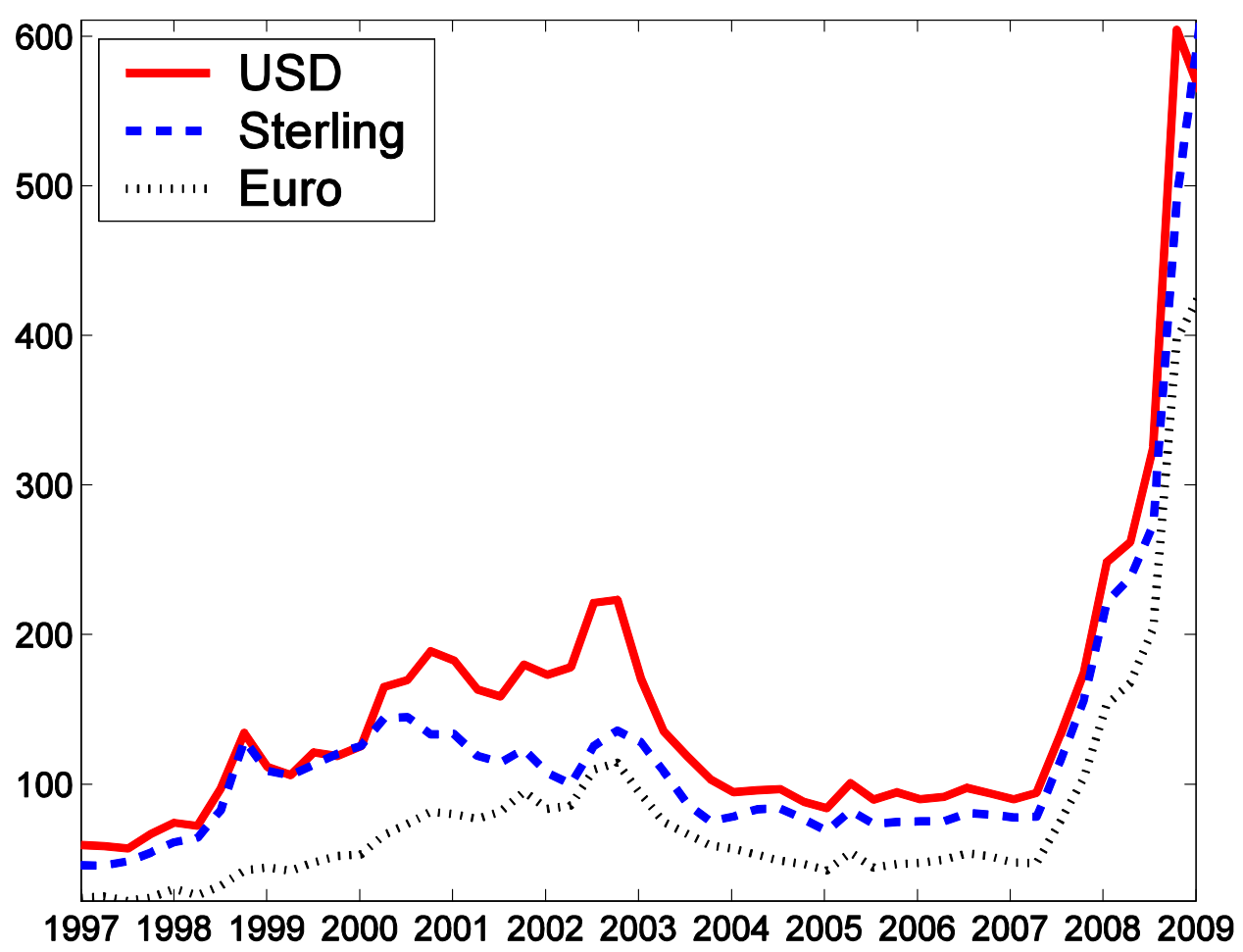

Investment grade corporate bond spreads (aggregate indices of bonds rated BBB3 or higher) 

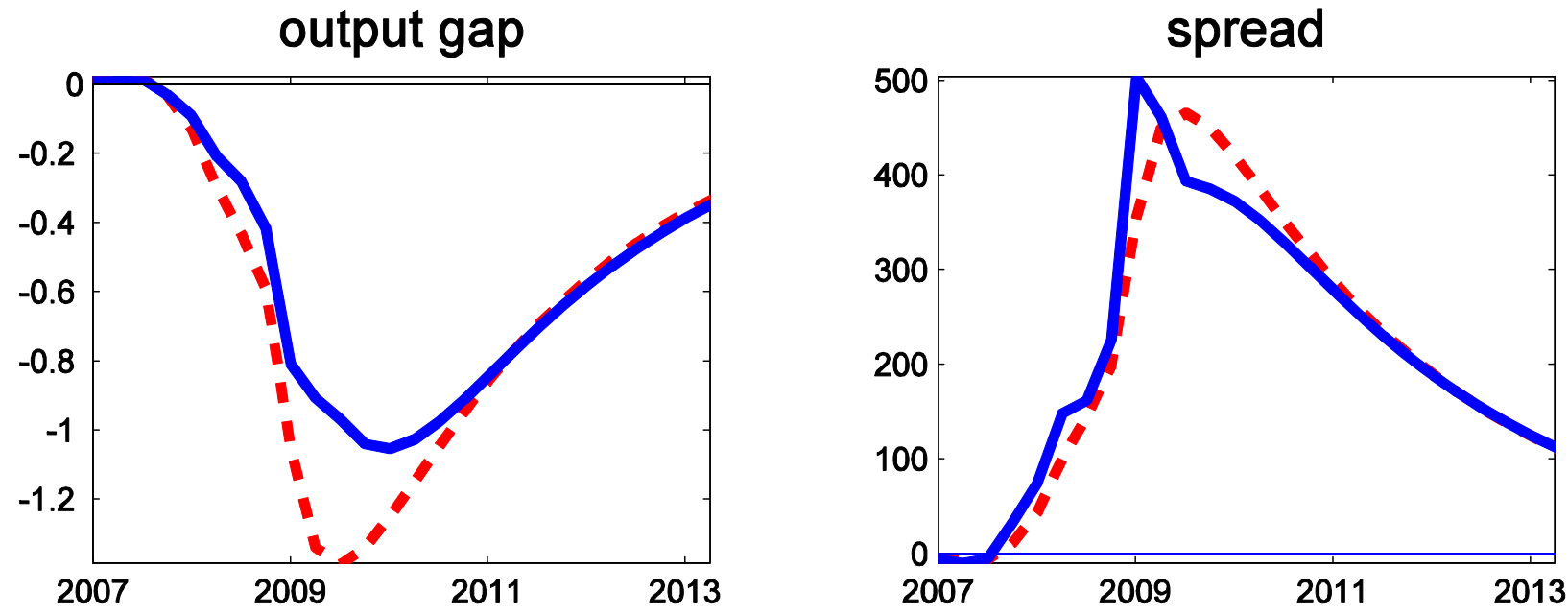

inflation
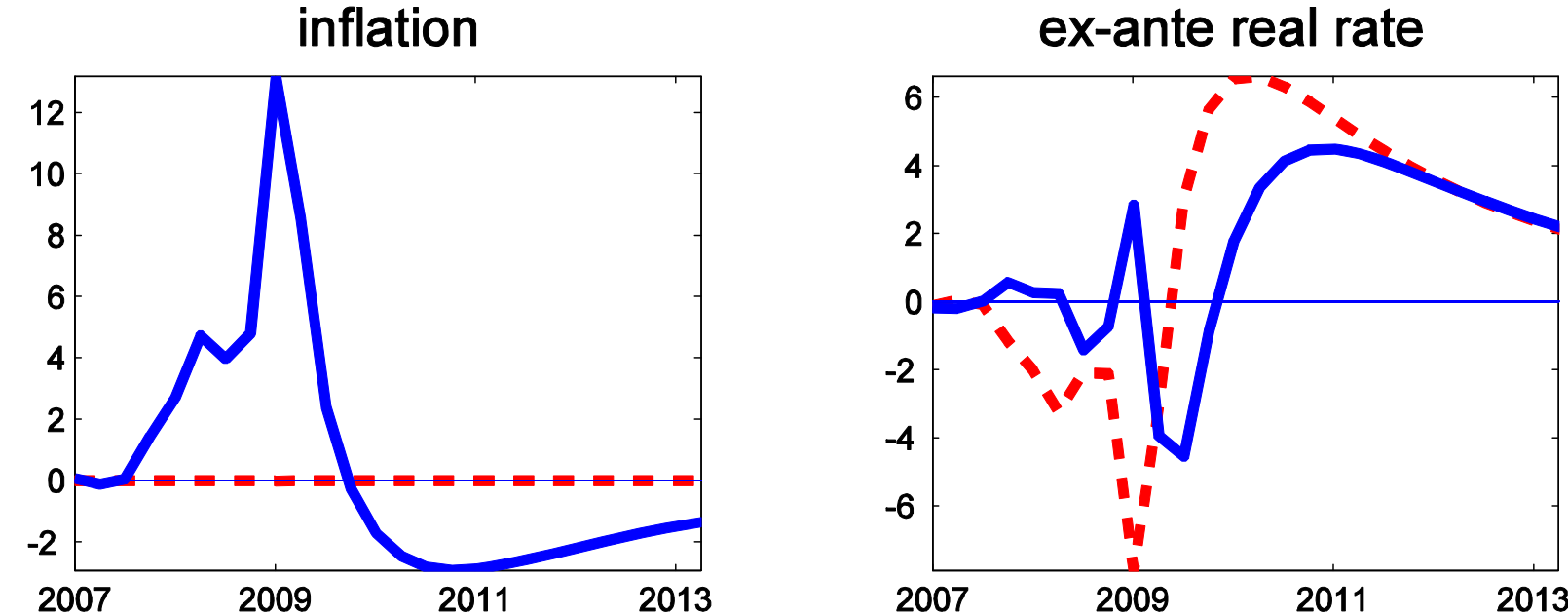

Evolution of the economy with net worth shocks only. Historical innovations until 2009Q1, zero innovations thereafter. Solid lines correspond to optimal monetary policy under commitment . Dashed lines are derived from a policy that fully stabilizes inflation. Inflation, the risk spread, and the real rate are annualized basis points. 

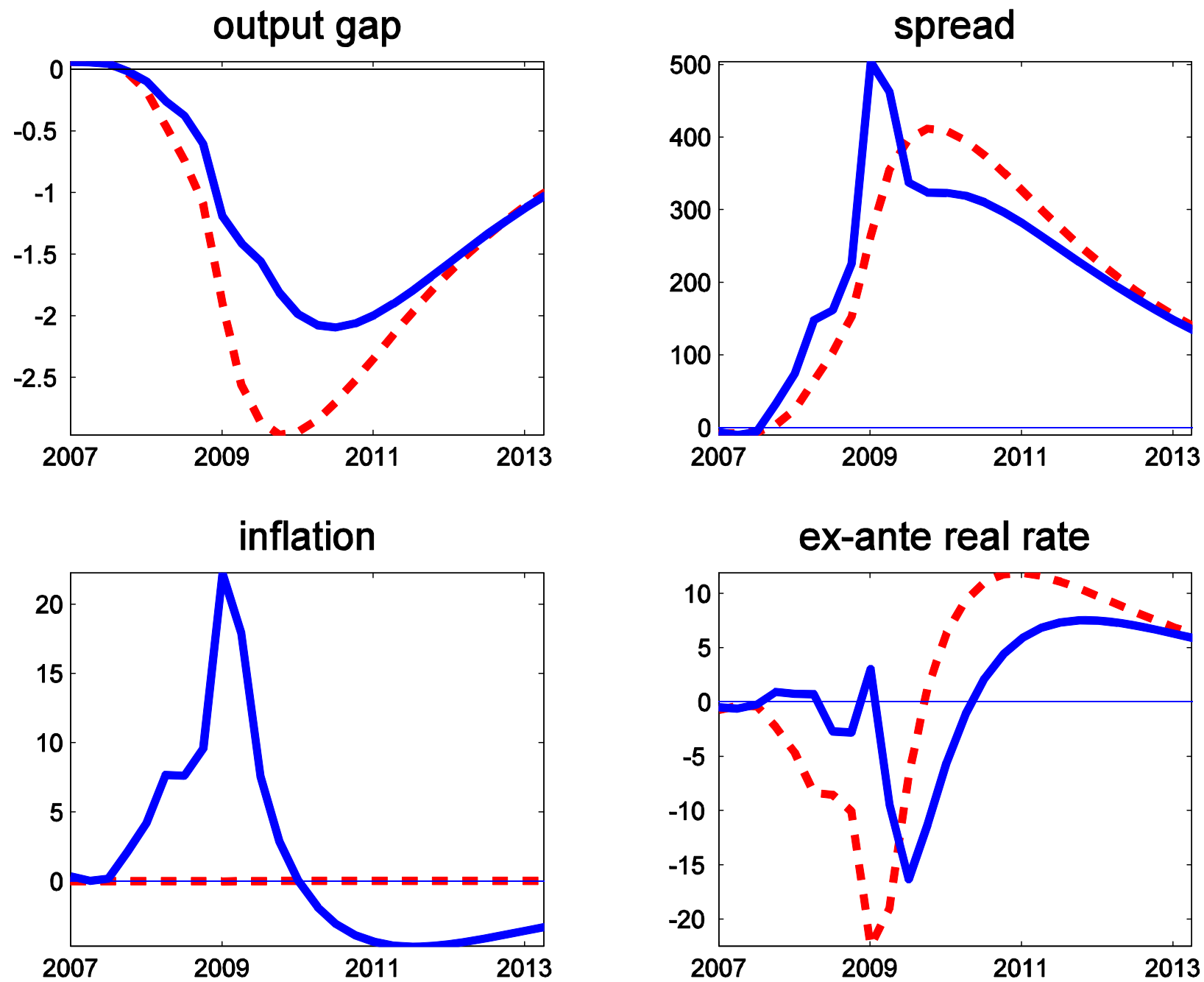

Inverse labor supply elasticity of $\theta=0.10$ Evolution of the economy with net worth shocks only. Historical innovations until 2009Q1, zero innovations thereafter. Solid lines correspond to optimal monetary policy under commitment. Dashed lines are derived from a policy that fully stabilizes inflation. Inflation, the risk spread, and the real rate are annualized basis points. 


\section{APPENDIX}

\section{The model in log-deviations.}

$$
\begin{aligned}
& \sigma \hat{y}_{t}+\theta \hat{L}_{t}=\widehat{w}_{t} \\
& \sigma \hat{y}_{t}+\theta \hat{u}_{t}=\hat{r}_{t} \\
& \sigma\left(E_{t} \hat{y}_{t+1}-\hat{y}_{t}\right)=\hat{R}_{t}-E_{t} \hat{\pi}_{t+1} \\
& \hat{q}_{t}=\beta E_{t} \hat{q}_{t+1}+(1-\beta) E_{t} \hat{d}_{t+1}-\sigma\left(E_{t} \hat{y}_{t+1}-\hat{y}_{t}\right) \\
& \hat{e}_{t}+\hat{q}_{t}=\hat{z}_{t}+\hat{y}_{t} \\
& \widehat{w}_{t}+\hat{L}_{t}=\hat{e}_{t-1}+\beta \hat{q}_{t}+(1-\beta) \hat{d}_{t}+\hat{n}_{t} \\
& \hat{z}_{t}+\hat{y}_{t}=\hat{r}_{t}+\hat{u}_{t} \\
& \hat{y}_{t}=\hat{a}_{t}+(1-\alpha) \hat{u}_{t}+\alpha \hat{L}_{t} \\
& \hat{\pi}_{t}=\lambda \hat{z}_{t}+\beta E_{t} \hat{\pi}_{t+1}+\lambda \epsilon_{t}^{\pi} \\
& \hat{d}_{t}=\hat{y}_{t}-(\varepsilon-1) \hat{z}_{t} . \\
& \hat{\phi}_{t}=\hat{z}_{t}+\hat{y}_{t}-\widehat{w}_{t}-\hat{L}_{t}
\end{aligned}
$$

where we have used the fact that $\hat{p}_{t}=\hat{z}_{t}+\hat{a}_{t}$ and $\hat{c}_{t}=\hat{y}_{t}=\hat{a}_{t}+\hat{x}_{t}$. The system is closed with a policy rule for the nominal interest rate. 


\section{A more general collateral constraint.}

Here we consider a more generalized version of the collateral constraint. Suppose that if the entrepreneurs try to hold up the L-suppliers, these suppliers can seize the entrepreneur's net worth and/or part of the profit flow left over after paying the u-suppliers. We generalize this with a Cobb-Douglass constraint given by:

$$
w_{t} L_{t} \leq g\left(n_{t}, p_{t} x_{t}-r_{t} u_{t}\right) \equiv \kappa n_{t}^{b}\left(p_{t} x_{t}-r_{t} u_{t}\right)^{1-b}
$$

where $n_{t} \equiv e_{t-1}\left(Q_{t}+D_{t}\right)$. The paper uses $\kappa=\mathrm{b}=1$. Let $\phi_{t}$ denote the multiplier on this constraint. The entrepreneur's FONC are now given by:

$$
\begin{aligned}
& \alpha p_{t} x_{t}\left[1+\phi_{t} g_{2}(t)\right]=w_{t} L_{t}\left(1+\phi_{t}\right) \\
& (1-\alpha) p_{t} x_{t}=r_{t} u_{t}
\end{aligned}
$$

Entrepreneurial profits are given by

$$
\text { profits }_{t}=\alpha p_{t} x_{t}-w_{t} L_{t}=\alpha p_{t} x_{t}\left(\frac{\phi_{t}\left(1-g_{2}(t)\right)}{1+\phi_{t}}\right)
$$

An alternative way to write (A15) is

$$
\text { profits }_{t}=\alpha p_{t} x_{t}-w_{t} L_{t}=\alpha p_{t} x_{t}-\frac{\alpha p_{t} x_{t} g_{2}(t)}{1-b}=\alpha p_{t} x_{t}\left(\frac{1-b-g_{2}(t)}{1-b}\right)
$$

Equating (A15) and (A16) implies that

$$
g_{2}(t)=\frac{1-b}{1+b \phi_{t}}
$$

Using this we can write (A13) and (A15) as:

$$
\alpha p_{t} x_{t}=w_{t} L_{t}\left(1+b \phi_{t}\right)
$$




$$
\text { profits }_{t}=\alpha p_{t} x_{t}\left(\frac{b \phi_{t}}{1+b \phi_{t}}\right)
$$

The entrepreneur's budget constraint is given by

$$
c_{t}^{e}+e_{t} Q_{t} \leq n_{t}+\text { profits }_{t}
$$

Equation (A17) implies that $g(t)=\alpha p_{t} x_{t}\left(\frac{1}{1+b \phi_{t}}\right)$ so that the collateral constraint can be written as

$$
\left(\frac{1}{\kappa\left(1+b \phi_{t}\right)}\right)^{1 / b}=\frac{n_{t}}{\alpha p_{t} x_{t}}
$$

We can think of the risk premium as the extra cost of employing the L-input compared to the $\mathrm{u}-$ input. This implies that $\left(1+r p_{t}\right)=\frac{\left(1+\phi_{t}\right)}{\left[1+\phi_{t} g_{2}(t)\right]}=\left(1+b \phi_{t}\right)$. Equation $(\mathrm{A} 21)$ thus implies that risk premium is inversely related to the net-worth to project-size ratio. Equation (A20) can be written as:

$$
c_{t}^{e}+e_{t} Q_{t} \leq \alpha p_{t} x_{t}\left[\left(\frac{b \phi_{t}}{1+b \phi_{t}}\right)+\left(\frac{1}{\kappa\left(1+b \phi_{t}\right)}\right)^{1 / b}\right]
$$

Hence, compared to the model in the text $(\kappa=b=1)$, we have

$$
\begin{aligned}
& w_{t} L_{t}=\kappa n_{t}^{b}\left(\alpha p_{t} x_{t}\right)^{1-b} \\
& \alpha p_{t} x_{t}=w_{t} L_{t}\left(1+b \phi_{t}\right) \\
& e_{t} Q_{t}=\gamma \alpha p_{t} x_{t}\left[\left(\frac{b \phi_{t}}{1+b \phi_{t}}\right)+\left(\frac{1}{\kappa\left(1+b \phi_{t}\right)}\right)^{1 / b}\right]
\end{aligned}
$$




\section{Steady-state and subsidies.}

In the steady state we will choose subsidies for L-wages $\left(w_{s u b}\right)$ and u-wages $\left(r_{s u b}\right)$ to achieve the efficient steady-state. In particular we have:

$$
\begin{gathered}
B_{1} c_{s S}^{\sigma} L_{s s}^{\theta}=w_{s s}\left(1+w_{s u b}\right) \\
B_{2} c_{s s}^{\sigma} u_{s s}^{\theta}=r_{s s}\left(1+r_{s u b}\right) \\
Q_{s s}=\frac{\beta}{1-\beta} D_{s s} \\
Z_{s s}=P_{s s}=\frac{\varepsilon-1}{\varepsilon} \\
D_{s s}=X_{s s}\left(1-Z_{s s}\right) \\
P_{s s} M P L_{s s}=w_{s s}\left(1+\phi_{s s}\right) \\
P_{s s} M P U_{s s}=r_{s s} \\
e_{s s} Q_{s s}=\gamma \alpha P_{s S} x_{s s} \\
e_{s s}\left(Q_{s s}+D_{s s}\right)=w_{s s} L_{s s} \\
c_{s s}=x_{s s}
\end{gathered}
$$

We pick the subsidies so that the first-best level of output is achieved:

$$
\begin{gathered}
B_{1} c_{s s}^{\sigma} L_{s s}^{\theta}=M P L_{s s} \frac{Z_{s s}}{\left(1+\phi_{s s}\right)}\left(1+w_{s u b}\right)=M P L_{s s} \\
B_{2} c_{s s}^{\sigma} u_{s s}^{\theta}=M P U_{s s} Z_{s s}\left(1+r_{s u b}\right)=M P U_{s s}
\end{gathered}
$$

Note that the only steady-state value that affects the log-linearized dynamics is the steady state value of $z$. 


\section{Deterministic Dynamics.}

Flexible prices. In the case of flexible prices the characteristic equation of the deterministic system is quadratic and is given by:

$$
h(x) \equiv \beta x^{2}-(1+\beta A) x+A .
$$

where $A \equiv \frac{\alpha(1-\sigma)}{\alpha(1-\sigma)+\theta+\sigma}$. The roots are $1 / \beta$ and A. Hence, there is determinacy if and only if A is in the unit circle. For $\sigma>1$, A is in the unit circle as long as $\alpha$ is not too large. Let $\alpha_{c u t}$ denote the upper bound for $\alpha$. We have:

$$
\alpha_{c u t}=\frac{1}{2}\left(\frac{(\theta+\sigma)}{(\sigma-1)}\right), \text { for } \sigma>1 .
$$

In summary, for flexible prices there is a unique positive root if and only if $\sigma<1$. If $\sigma>1$, the system is exactly determined if $\alpha<\alpha_{\text {cut. }}$. But in this case there are oscillatory dynamics. If $\sigma>1$, and $\alpha>\alpha_{\text {cut }}$, the system is over-determined.

Sticky prices. In this case the characteristic equation of the system is a quartic. With one predetermined variable, there must be one stable eigenvalue for determinacy. This eigenvalue will determine the deterministic dynamics of the system. Let $\mathrm{f}(\mathrm{x})$ denote this quartic. We have the following:

$$
\begin{aligned}
& f(1)=\frac{1-\beta}{\beta} \\
& f(0)=\alpha\left(\frac{\sigma(1+\tau \lambda)-\tau \lambda}{\beta D}\right)
\end{aligned}
$$

where $D \equiv\{\tau \lambda(\sigma+\theta)+\sigma[1-\alpha(1-\beta)(1+m)]\}$. We assume that $\mathrm{D}>0$ which will hold for all typical calibrations. We are interested in the nature of the dynamics, so let us assume that we have determinacy. Since $\mathrm{f}(1)>0$, the (assumed-to-be) unique stable root is positive if and only 
if $\mathrm{f}(0)<0$ or $\sigma<\frac{\lambda \tau}{1+\lambda \tau}$. This bound is independent of $\alpha$. In contrast, if $\sigma>\frac{\lambda \tau}{1+\lambda \tau}$, then $\mathrm{f}(0)>0$ so that the stable root is negative.

As with the flexible price model, it is possible for the system to be over-determined. A necessary condition for determinacy is that $\mathrm{f}(-1)<0$. This is satisfied if $\alpha<\alpha_{\text {cut }}$, where

$$
\begin{aligned}
& \alpha_{c u t}=\frac{\lambda(\tau+1)(\sigma+\theta)+2 \sigma(1+\beta)}{2[\lambda(\tau+1)(\sigma-1)+2 \sigma(1+\beta)]} \text { if } \sigma>\frac{\lambda(\tau+1)}{[\lambda(\tau+1)+2(1+\beta)]} \\
& \alpha_{c u t}=1 \text { if } \sigma<\frac{\lambda(\tau+1)}{[\lambda(\tau+1)+2(1+\beta)]} .
\end{aligned}
$$

Numerical simulations suggest that when $\alpha>\alpha_{\text {cut }}$ (so that $\mathrm{f}(-1)>0$ and $\mathrm{f}(1)>0$ ) the model is typically overdetermined. (Note that $\alpha_{\text {cut }}$ collapses to the flexible price expression as $\lambda \rightarrow \infty$.) This cut-off is decreasing in $\sigma$ so that the smallest it can be (as we vary $\sigma$ ) is $1 / 2$.

It is possible that $\sigma<\frac{\lambda \tau}{1+\lambda \tau}$ (so that $\left.\mathrm{f}(0)<0\right)$ and $\alpha>\alpha_{\text {cut }}$ (so that $\mathrm{f}(-1)>0$ ), so that the system is underdetermined (two roots in the unit circle). However, this indeterminacy does not arise for plausible calibrations. To see this note that $\alpha_{c u t}$ is decreasing in $\sigma$ so that the smallest $\alpha_{c u t}$ can be is given by setting $\sigma=\frac{\lambda \tau}{1+\lambda \tau}$ so that we have

$$
\alpha_{\text {cut }}\left(\text { with } \sigma=\frac{\lambda \tau}{1+\lambda \tau}\right)=\frac{1}{2}+\left(\frac{1+\theta}{2}\right)\left(\frac{(\tau+1)(\lambda \tau+1)}{2 \beta \tau+\tau-1}\right)
$$

For typical calibrations this is greater than one so that $\alpha>\alpha_{\text {cut }}$ will not be satisfied.

In summary, assuming that there is only one root in the unit circle, the dynamics are characterized as follows: (i) if $\sigma<\frac{\lambda \tau}{1+\lambda \tau}$ the single root is positive so that there are nonoscillatory dynamics, (ii) this root is zero if $\sigma=\frac{\lambda \tau}{1+\lambda \tau}$ so that there are no deterministic dynamics, 
and (iii) this root is negative if $\sigma>\frac{\lambda \tau}{1+\lambda \tau}$ so that there are oscillatory dynamics. In this latter case, there is an upper bound on the value of $\alpha$ given by $\alpha_{c u t}$, in which the system is typically over-determined if $\alpha>\alpha_{\text {cut }}$.

\section{Proofs.}

\section{Proposition 1:}

The gross inflation rate that maximizes a present value welfare criterion is unity in the steady state regardless of whether subsidies exist that make the steady state efficient.

\section{Proof:}

The policymaker maximizes $W_{0}=E_{t} \sum_{t=0}^{\infty} \beta^{t} U_{t}$, where $U$ is the period utility function, subject to the nonlinear equilibrium conditions. For this proof, we only need to consider those constraints that involve the inflation rate, i.e. the resource constraint and the price setting equation. These are:

$$
\begin{aligned}
& C_{t}=A_{t} L_{t}^{\alpha} U_{t}^{1-\alpha}\left(1-\frac{\varphi}{2}\left(\pi_{t}-1\right)^{2}\right) \\
& \left((\varepsilon-1)-\varepsilon Z_{t}+\varphi\left(\pi_{t}-1\right) \pi_{t}\right) Y_{t} C_{t}^{-\sigma}=E_{t} \varphi \beta\left(\pi_{t+1}-1\right) \pi_{t+1} Y_{t+1} C_{t+1}^{-\sigma}
\end{aligned}
$$

Here, $\varepsilon$ is the elasticity of the final goods bundler. Let $\lambda_{t}^{1}$ and $\lambda_{t}^{2}$, respectively, denote the Lagrange multipliers on these constraints. The first-order condition of the Ramsey planner problem for choice of $\pi_{t}$ evaluated at the steady state is

$$
0=\lambda_{S S}^{1} \varphi\left(\pi_{S S}-1\right) \mathrm{A}_{S S} L_{S S}^{\alpha} U_{S S}^{1-\alpha}
$$

The resource constraint is a binding constraint on the policymaker, $\lambda_{S S}^{1}>0$, consequently the optimal steady state gross inflation rate is unity. Since none of the constraints used in this proof depend on subsidies, the results holds regardless of whether subsidies exist that render the steady state efficient. QED.

Proposition 2: A quadratic approximation to the welfare function around the zero net inflation steady state is given by:

$\frac{U(t)-U^{*}(t)}{U_{c}(s s) c_{s s}} \approx-\frac{1}{2}\left[\frac{(\varepsilon-1)}{\lambda} \hat{\pi}_{t}^{2}+(\sigma+\theta)\left(\hat{y}_{t}^{g}\right)^{2}+\frac{\alpha(1-\alpha)}{1+\theta} \hat{\phi}_{t}^{2}\right]+t i p$ 


\section{Proof:}

For ease of exposition, we derive the welfare function in terms of absolute deviations and then convert to percentage deviations in the last step. We define $\tilde{X}_{t} \equiv X_{t}-X_{S S}$ as absolute deviations from the steady state and $\hat{X}_{t} \equiv\left(X_{t}-X_{S S}\right) / X_{S S}$ as percentage deviations. In a first step, we take a quadratic approximation to the utility functional:

$$
\begin{aligned}
U(t)-U(s s) & \approx U_{c} \tilde{c}_{t}+U_{L} \tilde{L}_{t}+U_{u} \hat{u}_{t}+\frac{1}{2}\left(U_{c c} \tilde{c}_{t}{ }^{2}+U_{L L} \tilde{L}_{t}{ }^{2}+U_{u u} \tilde{u}_{t}^{2}\right)+U_{c L} \tilde{c}_{t} \tilde{L}_{t}+U_{c u} \tilde{c}_{t} \tilde{u}_{t} \\
& +U_{L u} \tilde{c}_{t} \tilde{L}_{t}
\end{aligned}
$$

The resource constraint is given by:

$$
c_{t}=A_{t} L_{t}^{\alpha} u_{t}^{1-\alpha}\left[1-\frac{\varphi\left(\pi_{t}-1\right)^{2}}{2}\right] \equiv A_{t} f\left(L_{t}, u_{t}\right)\left[1-\frac{\varphi\left(\pi_{t}-1\right)^{2}}{2}\right]
$$

A quadratic approximation to this expression is given by: (note that $\left.\pi_{\mathrm{ss}}=1\right)$

$$
\begin{gathered}
\tilde{c}_{t} \approx c_{s s} \tilde{A}_{t}+f_{L}(s s) \tilde{L}_{t}+f_{u}(s s) \tilde{u}_{t}+\frac{1}{2}\left(f_{L L}(s s) \tilde{L}_{t}{ }^{2}+f_{u u}(s s) \tilde{u}_{t}{ }^{2}-c_{s s} \varphi \tilde{\pi}_{t}^{2}\right)+f_{L A}(s s) \tilde{L}_{t} \tilde{A}_{t} \\
+f_{u A}(s s) \tilde{u}_{t} \tilde{A}_{t}+f_{L u}(s s) \tilde{L}_{t} \tilde{u}_{t}
\end{gathered}
$$

Since we have assumed separable utility, and that the steady-state is efficient, we have:

$$
\begin{aligned}
& U(t)-U(s s) \approx \frac{1}{2}\left(U_{c c} \tilde{c}_{t}^{2}+U_{L L} \tilde{L}_{t}^{2}+U_{u u} \tilde{u}_{t}^{2}\right)+\frac{1}{2} U_{c}\left(f_{L L}(s s) \check{L}_{t}^{2}+f_{u u}(s s) \tilde{u}_{t}^{2}-c_{s s} \varphi \tilde{\pi}_{t}^{2}+\right. \\
& \left.f_{L A}(s s) \tilde{L}_{t} \tilde{A}_{t}+f_{u A}(s s) \tilde{u}_{t} \tilde{A}_{t}+f_{L u}(s s) \tilde{L}_{t} \tilde{u}_{t}\right)+t i p
\end{aligned}
$$

Here, tip denotes terms independent of policy. Since all of these terms are of second order, we now only need consider linear terms in the subsequent expansions. The equilibrium choice of $u$ is given by:

$$
U_{u}(t)=U_{c}(t) f_{u}(t) P_{t}
$$

Log-linearizing this expression and imposing efficiency in the steady-state, we have:

$$
\hat{u}_{t}=\frac{\alpha(1-\sigma)}{\alpha(1-\sigma)+(\sigma+\theta)} \hat{L}_{t}+\frac{1}{\alpha(1-\sigma)+(\sigma+\theta)} \hat{z}_{t}+\frac{(1-\sigma)}{\alpha(1-\sigma)+(\sigma+\theta)} \hat{a}_{t}
$$

We will use this expression to eliminate $u$ from the welfare function (1).

Labor choice can be characterized this way:

$$
U_{u}(t) f_{L}(t)=U_{L}(t) f_{U}(t)\left(1+\phi_{t}\right)
$$

Expanding this up to the first order (and imposing efficiency in the steady-state) we have: 


$$
\widehat{\phi}_{t}=(\theta+1) \hat{u}_{t}-(\theta+1) \hat{L}_{t}
$$

The efficient response to shocks is easily found by setting $\hat{z}_{t}=\hat{\phi}_{t}=0$.

$$
\begin{gathered}
\hat{L}_{t}^{e}=\frac{(1-\sigma)}{(\sigma+\theta)} \hat{a}_{t} \\
\hat{u}_{t}^{e}=\frac{(1-\sigma)}{(\sigma+\theta)} \hat{a}_{t}
\end{gathered}
$$

We now define the labor gap to be the gap between actual labor and efficient labor. Substituting this into (1), simplifying and subtracting the same approximations in an efficient economy with flexible prices and no credit frictions (which is independent of policy), we have

$\frac{U(t)-U^{*}(t)}{U_{c}(s s) c_{s s}} \approx-\frac{1}{2}\left[\varphi \hat{\pi}_{t}^{2}+\frac{\alpha(1+\theta)(\sigma+\theta)}{\theta+\alpha+\sigma(1-\alpha)}\left(\hat{L}_{t}^{g}\right)^{2}+\frac{1-\alpha}{\theta+\alpha+\sigma(1-\alpha)} \hat{z}_{t}^{2}\right]$

Next, we use $\lambda=(\epsilon-1) / \varphi$ to rewrite the weight on inflation in terms of the slope of the Phillips curve. Using (16) and (17) to eliminate $\hat{z}_{t}^{2}$ and $\left(\hat{L}_{t}^{g}\right)^{2}$, we arrive at

$\frac{U(t)-U^{*}(t)}{U_{c}(s s) c_{s s}} \approx-\frac{1}{2}\left[\frac{(\varepsilon-1)}{\lambda} \hat{\pi}_{t}^{2}+(\sigma+\theta)\left(\hat{y}_{t}^{g}\right)^{2}+\frac{\alpha(1-\alpha)}{1+\theta} \hat{\phi}_{t}^{2}\right]$

QED.

Proposition 3: The optimal inflation target under commitment from a timeless perspective is given by:

$$
\begin{gathered}
\hat{\pi}_{t}=\left[\frac{\alpha \varepsilon(1-\beta)-1}{\varepsilon-1}\right] \Delta \hat{y}_{t}^{g}-\left[\frac{\alpha \varepsilon(1-\beta)(1-\alpha)}{(\varepsilon-1)(1+\theta)}\right] \Delta \hat{\phi}_{t}-\left[\frac{\alpha \varepsilon(1-\beta)(\sigma-1)+1+\theta}{(\varepsilon-1)(\sigma+\theta)}\right] \hat{X}_{t} \\
+\left[\frac{\varepsilon(1-\beta)[\alpha(\sigma-1)-(\sigma+\theta)]+1+\theta}{\beta(\varepsilon-1)(\sigma+\theta)}\right] \hat{X}_{t-1}
\end{gathered}
$$

With $\hat{X}_{t}$ as given by (34) in the text.

\section{$\underline{\text { Proof }}$}

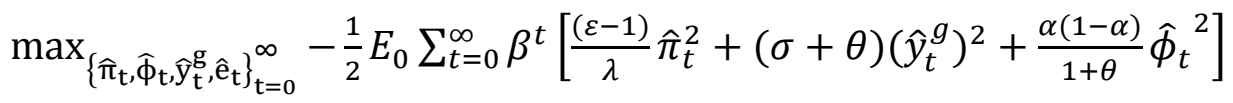

subject to: 


$$
\begin{aligned}
& \hat{\pi}_{t}=\lambda(\sigma+\theta) \hat{y}_{t}^{g}+\alpha \lambda \hat{\phi}_{t}+\beta E_{t} \hat{\pi}_{t+1}+\lambda \epsilon_{t}^{\pi}, \\
& \hat{e}_{t}=\frac{1}{\beta}\left\{\hat{e}_{t-1}-\varepsilon(1-\beta)(\sigma+\theta) \hat{y}_{t}^{g}+[1-\alpha \varepsilon(1-\beta)] \hat{\phi}_{t}+n_{t}\right\}, \\
& \hat{\phi}_{t}=(1+\theta) E_{t} \Delta \hat{y}_{\mathrm{t}+1}^{\mathrm{g}}-(1-\alpha) E_{t} \Delta \hat{\phi}_{t+1}-\frac{(\sigma-1)(1+\theta)}{\sigma+\theta} E_{t} \Delta \hat{a}_{\mathrm{t}+1}-E_{t} n_{\mathrm{t}+1}
\end{aligned}
$$

Let $\mu_{t}^{1}, \mu_{t}^{2}, \mu_{t}^{3}$ denote the Lagrange multipliers associated with (A27)-(A29). The first-order conditions for $t>0$ are:

$$
\begin{aligned}
& 0=-\frac{(\varepsilon-1)}{\lambda} \hat{\pi}_{t}-\mu_{t}^{1}+\mu_{t-1}^{1} \\
& 0=-(\sigma+\theta) \hat{y}_{t}^{g}+\mu_{t}^{1} \lambda(\sigma+\theta)-\mu_{t}^{2} \frac{(1-\beta) \varepsilon(\sigma+\theta)}{\beta}-\mu_{t}^{3}(1+\theta)+\mu_{t-1}^{3} \frac{(1+\theta)}{\beta} \\
& 0=-\frac{\alpha(1-\alpha)}{1+\theta} \hat{\phi}_{t}+\mu_{t}^{1} \alpha \lambda+\mu_{t}^{2} \frac{(1-\alpha(1-\beta) \varepsilon)}{\beta}-\mu_{t}^{3} \alpha+\mu_{t-1}^{3} \frac{(\alpha-1)}{\beta} \\
& 0=-\mu_{t}^{2}+E_{t} \mu_{t+1}^{2}
\end{aligned}
$$

Solve (A31) and (A32) for $\mu_{t}^{1}$ and $\mu_{t}^{2}$. We scroll these expressions forward and backward to eliminate all leads and lags of $\mu_{t}^{1}$ and $\mu_{t}^{2}$ from the system. Equations (A30) and (A34) can now be expressed in terms of $\Delta \mu_{t}^{3}, \Delta \mu_{t-1}^{3}, \Delta \mu_{t+1}^{3}, \Delta \hat{y}_{t}^{g}, \Delta \hat{y}_{t+1}^{g}, \Delta \hat{\phi}_{t}$, and $\Delta \hat{\phi}_{t+1}$. The term $\hat{X}_{t}$ is proportional to $\Delta \mu_{t}^{3}$. We can then express the targeting criterion as in the Proposition. QED. 


\section{References}

Bernanke, B., and M. Gertler (1989), "Agency Costs, Net Worth and Business Fluctuations," American Economic Review (79), 14-31.

Bernanke, B., M. Gertler, and S. Gilchrist (1999), The Financial Accelerator in a Quantitative Business Cycle Framework," in J.B. Taylor and M. Woodford, eds., Handbook of Macroeconomics, vol. 1C, Amsterdam: North-Holland, 1999.

Bernanke, B., and M. Gertler (2001), "Should Central Banks Respond to Movements in Asset Prices," American Economic Review Papers and Proceedings 91, 253-257.

Carlstrom, C.., and T. Fuerst (1997), "Agency Costs, Net Worth, ad Business Fluctuations: A Computable General Equilibrium Analysis”. American Economic Review 87, pp. 893-910.

Carlstrom, C., and T. Fuerst (1998), "Agency Costs and Business Cycles”. Economic Theory, 12, pp. 583-597.

Carlstrom, C., and T. Fuerst (2001), "Monetary Shocks, Agency Costs and Business Cycles," Carnegie-Rochester Series on Public Policy 51: 1-27.

Carlstrom, C., and T. Fuerst (2007), "Asset Prices, Nominal Rigidities, and Monetary Policy," Review of Economic Dynamics 10(2), April 2007, 256-275.

Curdía, V. and M. Woodford (2008), Credit Frictions and Optimal Monetary Policy, National Bank of Belgium Working Paper No 146.

De Fiore, F., and O. Tristani (2008) "Optimal Monetary Policy in a Model of the Credit Channel”, Mimeo, European Central Bank.

Faia, E., and T. Monacelli (2007), Optimal Interest-Rate Rules, Asset Prices, and Credit Frictions," Journal of Economic Dynamics and Control 31:3228-3254.

Goodfriend, M., and B.. McCallum (2007), "Banking and Interest Rates in Monetary Policy Analysis: A Quantitative Exploration," Journal of Monetary Economics 54: 1480-1507.

Gilchrist, S. and J. Leahy, (2002) "Monetary Policy and Asset Prices", Journal of Monetary Economics, 2002 49: 75-97.

Hart, O., and J. Moore (1994), A Theory of Debt Based on the Inalienability of Human Capital," Quarterly Journal of Economics, 109, 841-879.

Iacoviello, M. (2005) "House prices, Borrowing Constraints and Monetary Policy in the Business Cycle", American Economic Review, 95: 739-764.

Keen, Benjamin D. and Yongsheng Wang, "What is a realistic value for price adjustment costs in New Keynesian Models?” Texas Tech University working paper, September 2004.

Kiyotaki, N. and J. Moore (1997), "Credit Cycles," Journal of Political Economy, 105(2), 211 248.

Rotemberg, Julio J. (1982), 'Sticky Prices in the United States,' Journal of Political Economy, 90, 1187-1211.

Woodord, Michael, Interest and Prices, Princeton University Press, 2003. 